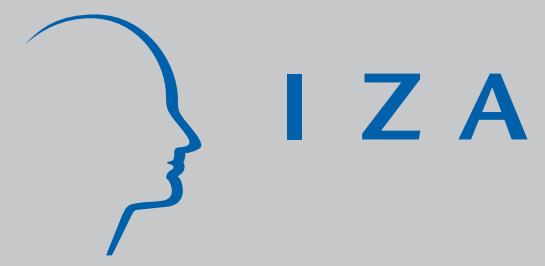

IZA DP No. 7946

The Effect of Behavioral Codes and Gender on Honesty

Yuval Arbel

Ronen Bar-El

Erez Siniver

Yossef Tobol

February 2014

Forschungsinstitut zur Zukunft der Arbeit Institute for the Study of Labor 


\title{
The Effect of Behavioral Codes and Gender on Honesty
}

\author{
Yuval Arbel \\ Carmel Academic Center \\ Ronen Bar-EI \\ Open University, Raanana \\ Erez Siniver \\ College of Management, Rishon Lezion Campus \\ Yossef Tobol \\ Jerusalem College of Technology, \\ Carmel Academic Center and IZA
}

Discussion Paper No. 7946

February 2014

\author{
IZA \\ P.O. Box 7240 \\ 53072 Bonn \\ Germany \\ Phone: +49-228-3894-0 \\ Fax: +49-228-3894-180 \\ E-mail: iza@iza.org
}

Any opinions expressed here are those of the author(s) and not those of IZA. Research published in this series may include views on policy, but the institute itself takes no institutional policy positions. The IZA research network is committed to the IZA Guiding Principles of Research Integrity.

The Institute for the Study of Labor (IZA) in Bonn is a local and virtual international research center and a place of communication between science, politics and business. IZA is an independent nonprofit organization supported by Deutsche Post Foundation. The center is associated with the University of Bonn and offers a stimulating research environment through its international network, workshops and conferences, data service, project support, research visits and doctoral program. IZA engages in (i) original and internationally competitive research in all fields of labor economics, (ii) development of policy concepts, and (iii) dissemination of research results and concepts to the interested public.

IZA Discussion Papers often represent preliminary work and are circulated to encourage discussion. Citation of such a paper should account for its provisional character. A revised version may be available directly from the author. 


\section{ABSTRACT}

\section{The Effect of Behavioral Codes and Gender on Honesty ${ }^{*}$}

We examine the effect of adherence to behavioral codes, as measured by the degree of religiosity, on the level of honesty by conducting under-the-cup die experiments. The findings suggest that behavioral codes, which prohibit lying, offset the monetary incentive to lie. The highest level of honesty is found among young religious females while the lowest is found among secular females. Moreover, when the monetary incentive to lie is removed, the tendency of secular subjects to lie disappears. Given the strict separation between the secular and religious education systems the research findings confirm the importance of education in instilling ethical values.

JEL Classification: C91, D63, Z12

Keywords: honesty, religion, behavioral codes, ethical values

Corresponding author:

Ronen Bar-El

Department of Economics

Open University of Israel

Dorothy de Rothschild Campus

1 University Road

P. O. Box 808

Raanana 43107

Israel

E-mail: ronenba@openu.ac.il

\footnotetext{
* We wish to thank Robert Aumann, Shlomo Yitzhaki, Bradley Ruffle and seminar participants at the Jerusalem College of Technology for helpful comments. Any errors or views expressed in this paper are solely those of the authors.
} 


\section{Introduction}

Honesty plays an important role in modern economic life. The degree of honesty in an economy determines the extent to which sellers will refrain from utilizing their superior information regarding the quality of their goods and services in order to exploit consumers. ${ }^{1}$ It affects the productivity of employees ${ }^{2}$ and compliance with tax laws. Moreover, a low degree of honesty imposes costly monitoring expenses on the economy. The modern economy presents both direct and indirect opportunities to lie and even incentives to do so.

It is becoming increasingly clear in the economic literature that in contrast to the traditional economic view of homo-economicus the degree of honesty is not solely determined by the selfish maximization of personal monetary benefit ${ }^{3}$ and that gender, culture and other social and psychological factors also play an important role. ${ }^{4}$ In other words, in the absence of a punishment mechanism, individuals can be expected to lie in order to achieve monetary benefits unless they are constrained by a behavioral code.

The objective of this research is to examine the effect of behavioral codes on the degree of honesty. To accomplish this, we extend the under-the-cup die experiment originally developed by Fischbacher and Föllmi-Heusi (2013) by differentiating participants according to gender and degree of religiosity. The under-the-cup die experiment provides an incentive for participants to cheat in order to achieve monetary benefits since they know they won't be caught (thus eliminating the expected cost of lying).

Unfortunately, the degree of adherence to behavioral codes, which may prevent or reduce cheating, is not directly observable. In order to overcome this problem, we conducted three experiments and sorted the participants according to their degree of

\footnotetext{
${ }^{1}$ See Akerlof (1970).

${ }^{2}$ See Shapiro and Stiglitz (1984).

${ }^{3}$ Further discussion can be found in Gneezy (2005). Becker (1993) points out that: "The economic approach I refer to does not assume that individuals are motivated solely by selfishness or material gain. It is a method of analysis, not an assumption about particular motivation."

${ }^{4}$ See also Gneezy (2005), Mazar, On and Ariely (2008), Shalvi et al. (2011, 2012, 2013), Erat and Gneezy (2012), Houser et al. (2012) and Gino and Ariely (2012). For an extensive review of the literature, see Mazar and Ariely (2006).
} 
religiosity (the participants classified themselves either as secular, Orthodox or ultraOrthodox Jews) and gender.

Jewish Law prohibits lying. ${ }^{5}$ As is characteristic of the religious Jewish population in Israel, ${ }^{6}$ the Orthodox and ultra-Orthodox participants in our experiment attended religious schools from kindergarten through high school. ${ }^{7}$ Furthermore, most of the religious males in our sample continued their religious studies in yeshivas after high school. The religious school system focuses on the in-depth study of Jewish religious texts. In addition to the effect of religious schooling, the more religious segments tend to live in closed communities and to devote a significant amount of time to religious activities and studies. In these communities there is less exposure to the secular media (TV, secular radio stations, unsupervised internet, etc.), particularly in ultra-Orthodox communities. ${ }^{8}$ Thus, individuals in these communities are socialized to behave according to religious values by means of both the education system and the neighborhood effect. In short, religious students have been indoctrinated to follow a shared set of values and norms, including the prohibition against lying.

The first experiment was conducted simultaneously at two Israeli colleges: the College of Management, whose student population largely consists of secular Jews, and the Jerusalem College of Technology (hereinafter: JCT), whose student population consists primarily of Orthodox and ultra-Orthodox Jews. Unlike the College of Management, JCT is defined as a religious institution, which combines secular academic studies with Jewish religious studies. The JCT is thus committed to maintaining Jewish religious values and compliance with religious commandments, in addition to providing an academic education. This includes, among other things, the strict separation of females and males on different campuses. ${ }^{9}$

\footnotetext{
5 "Keep thee far from a false matter" (Exodus 23:7). The equivalent Christian position is expressed in St. Augustine's De Mendacio (On Lying), written in 395 AD: "To me, however, it seems certain that every lie is a sin..." Immanuel Kant (1787) also completely negates the use of lies.

${ }^{6}$ The majority of Jews in Israel are secular while among the religious population the vast majority are Orthodox or ultra-Orthodox, with only a minority classified as Reform or Conservative (denominations which are much more popular in the US).

${ }^{7}$ Secondary schools for Orthodox females are called "ulpenas", those for ultra-Orthodox females are called "seminars" and those for males are called "yeshivas".

${ }^{8}$ See also Berman (2000).

${ }^{9}$ Orthodox Judaism adheres to the interpretation and application of the laws in the Torah, as interpreted in the Talmud (the "Oral Law") and further developed and applied by later authorities. Ultra-Orthodox Judaism is even stricter in its adherence to religious laws. The participants in our experiment were
} 
Participants first filled out a detailed anonymous questionnaire and were then asked to throw a die once and report the outcome. The participant was alone and behind a curtain when throwing the die, so that the true outcome was known only to him. The payoffs in the first experiment increased with the reported outcome. ${ }^{10}$ Therefore, participants had a strong monetary incentive to report the highest possible number (i.e., six) regardless of the true outcome. The tendency to lie is likely to be a function of the participant's level of household income and may be constrained by obedience to a behavioral code. The use of a socio-demographic questionnaire enabled us to examine the differences in the level of honesty between secular, Orthodox and ultra-Orthodox participants while controlling for gender, age, income and other socio-demographic variables.

Following Fischbacher and Föllmi-Heusi (2013), we classify the group of subjects whose average report is statistically equal to six as "complete liars" and the group whose average report is statistically equal to five as "partial liars". A group whose average reported outcome does not exceed the expected outcome in a fair die throw will be classified as "honest". A simple way to test for honesty is therefore to compare the average reported outcome to the expected one in a fair die throw (i.e. 3.5) and to the expected outcomes for complete and partial liars. ${ }^{11}$ Another approach is to calculate the proportion of participants who report five or six within each group. If the group consists of "honest" participants, this proportion is expected not to exceed one-third (the probability of a five $\left(\frac{1}{6}\right)$ or six $\left(\frac{1}{6}\right)$ in a single throw of a fair die).

The findings of the first experiment suggest that adherence to a behavioral code, as measured by the degree of religiosity, plays an important role in determining the level of honesty. Specifically, secular females were found to be less honest than Orthodox and ultra-Orthodox females, even though they have higher income levels and

asked to classify themselves as either secular, Orthodox or ultra-Orthodox. The degree of adherence of Orthodox Jews is the most heterogeneous, ranging from close to secularism to very much like the ultraOrthodox.

${ }^{10}$ In our version of the experiment, the payoffs are in NIS (New Israeli Shekels where 1 shekel is roughly equal to 0.28 US dollars). In addition to the fixed payment of 20 NIS for participation, subjects who reported a throw of 1 received an additional 10 NIS, those who reported 2 received 20 NIS and so on. Also note that the minimum hourly wage in Israel is roughly 20 NIS. Thus, the minimal payoff is equal to the wage for about 1.5 hours of work and the maximal payoff is equal to about 4 hours. These payoffs are considerable for low-income students.

\footnotetext{
${ }^{11}$ The expected outcome of a fair die throw is $\frac{1}{6} \times[1+2+3+4+5+6]=3.5$
} 
therefore a lower incentive to lie. ${ }^{12}$ According to the statistical tests, secular females are "partial liars" while Orthodox and ultra-Orthodox females can be classified as "honest". Similarly, secular males were found to be less honest than Orthodox and ultra-Orthodox males.

In comparing the level of honesty between the genders, we find that the average outcome reported by secular females is significantly higher than that reported by secular, Orthodox or ultra-Orthodox males, as is their tendency to report five or six. In other words and contrary to other studies in which females were found to be more honest than males, ${ }^{13}$ our findings suggest that the lowest level of honesty is to be found among secular females.

The evidence that religious groups have a higher level of honesty is further strengthened by our findings that income is negatively correlated with degree of religiosity. Furthermore, among the secular subjects income increases with age while the opposite is the case among the Orthodox and ultra-Orthodox. In other words, Orthodox and ultra-Orthodox Jews have a greater incentive to lie than secular Jews. However, the indoctrination not to lie cancels out the monetary incentive.

The findings also suggest that young religious females have the highest level of honesty among the various groups. Thus, the reported outcomes of young Orthodox and ultra-Orthodox males are higher than those of young Orthodox and ultraOrthodox females. The tendency of young Orthodox and ultra-Orthodox males to report five is higher than that of corresponding females and also exceeds the probability of one-sixth expected in a fair die throw. The variance of the outcomes reported by the religious participants indicates that this is not a monolithic group and further emphasizes the role of education in instilling values of honesty.

In order to more clearly establish a link between the level of honesty among the secular participants and the monetary incentives they were given in the first experiment, we conducted a similar control experiment only among secular students at the College of Management. In the control experiment, subjects were offered only a

\footnotetext{
${ }^{12}$ Data on relative household income level is derived from the self-rankings of the subjects relative to the average after-tax monthly household income of 11,534 NIS. The data is in line with official published data (such as the 2009 survey by the Central Bureau of Statistics) which consistently report lower levels of household income among the ultra-Orthodox.

${ }^{13}$ See Gneezy (2005), Dreber and Johannesson (2008), Childs (2012), and Gylfason, Arnardottir and Kristinsson (2013).
} 
fixed payment of 55 NIS for participating regardless of the reported outcome. ${ }^{14}$ As expected, in the absence of a monetary incentive, the average reported outcome for both secular males and secular females was not significantly different from the average outcome of a fair die throw (3.5). In other words, in the absence of a monetary incentive to lie, the subjects reported honestly.

In order to test the robustness of the results, we replicated the first two experiments, except that this third experiment was conducted simultaneously among the various groups and in the same academic institution, i.e. the Carmel Academic Center in Haifa, whose students are mostly secular with a minority of Orthodox and ultraOrthodox students. Moreover, we improved the third experiment by randomly assigning either a fixed payoff (which does not create an incentive to lie) or an increasing payoff (which does) among the secular participants. The results of the third experiment reinforce those of the first two.

With respect to public policy implications, the results suggest that the level of honesty in an economy can be raised through education. This was demonstrated by the successful campaign against corruption in Hong Kong in 1974, which was designed to instill moral values and to alter social norms by means of the education system and the media (see Hauk and Saez-Marti 2002). By making honesty a social norm, a society can reduce the economic burden associated with dishonesty. Furthermore, when behavioral patterns become social norms, individuals gain personal benefit by complying with them as rules-of-thumb, even in the absence of a punishment mechanism (Aumann 1997 and Witt 2008).

This paper proceeds as follows: Section 2 presents a survey of the literature. Section 3 describes the experimental design. Section 4 presents the descriptive statistics for the first experiment. Section 5 describes the econometric model and the results of the first experiment. Sections 6 and 7 present the results of the second and third experiments, respectively. Finally, section 8 concludes and summarizes.

\section{Survey of the literature}

The notion that individuals are not completely selfish and dishonest dates back to Adam Smith (1759) who asserted that: "How selfish so ever man may be supposed, there are evidently some principles in his nature, which interest him in the fortune of

\footnotetext{
${ }^{14}$ A payoff of 55 NIS is equivalent to the expected payoff in the previous version of the experiment.
} 
others, and render their happiness necessary to him, though he derives nothing from it except the pleasure of seeing it."

The claim that moral behavior indeed exists can also be seen in the attitude toward lying, which has been investigated in the experimental literature. Gneezy (2005) found a higher tendency to lie when there is resulting personal gain, though it is constrained when a loss is incurred to other individuals. Charness and Dufwenberg (2006) provide evidence for the existence of guilt aversion which leads individuals to fulfill unbinding promises to other individuals. Lundquist, Ellingsen, Gribbe and Johannesson (2009) experimentally examine the effect of "cheap talk" in a bargaining game with one-sided asymmetric information. They provide evidence of lie-aversion, which increases with the magnitude of the lie. Pruckner and Sausgruber (2013) examined the willingness to pay 0.6 euro for a newspaper that could be obtained free of charge. They exposed individuals to various messages which appealed to their moral sentiment and persuaded them to pay more for the newspaper; however, the messages did not increase the proportion of individuals who decided to pay for a newspaper rather than take it free of charge. Their results indicate that people have a preference for honesty that is based on internalized social norms.

Bidner and Francois (2010) used data on 72 countries gathered by the World Values Survey to show that norms of trust and truth telling may be the result of wellfunctioning institutions of law enforcement and punishment.

Fischbacher and Föllmi-Heusi (2013) measured honesty by including two unique features in their experiment (which are also included in this study): the opportunity to lie without being caught and an objective mechanism for ranking the level of honesty. The participants received a die which they rolled unobserved. They received an additional 1,2,3,4 or 5 Swiss Francs for reporting the outcomes 1,2,3,4 or 5 respectively and no additional payment for reporting 6 . Thus, the subjects had an incentive to be dishonest and to report higher numbers than they had actually obtained. The results showed that the population can be categorized as "honest" (if the fraction of people reporting 6 is positive), "complete liars" (if the frequency of the number 5 exceeds that expected in a fair die throw, i.e. 1/6), and "partial liars" (if the frequency of the number 4 exceeds 1/6). In addition they conducted a series of experiments based on the same methodology and showed that changing the experimental setting does not significantly alter the results. In the second experiment, they multiplied the payoff by a factor of three (in order to compare the effect of higher and lower payoffs). 
In the third, subjects were asked to divide 5 Swiss Francs between them (based on the reported outcome of a die roll) and a third unknown party. In the fourth, they allowed for a repeated game. In the fifth, payoffs were given in sealed envelopes.

Several studies have investigated gender differences in the level of honesty. Dreber and Johannesson (2008) used the experimental design of Gneezy (2005) to investigate gender differences. Participants in their experiment are either "senders" or "receivers". Both parties have two options: action A, which yields 40 SEK (Swedish kronor) to the sender and 50 SEK to the receiver, and action B which yields 40 SEK (Swedish kronor) to the receiver and 50 SEK to the sender. Only the sender knows the true payoffs when he sends a message to the receiver to inform him which action he should choose. The message can either be true or false and the sender must decide whether to lie or tell the truth. Receivers have to decide whether to trust the senders. The results indicate that female senders lie less than male senders (38\% vs. 55\%). Childs (2012) also found that females are more honest than males while Gylfason, Arnardottir and Kristinsson (2013) found that there are no gender differences with respect to honesty.

Erat and Gneezy (2010) distinguish between four different types of lies. The type closest to that in Fischbacher and Föllmi-Heusi (2013)'s setting is the selfish black lie where the liar receives a payoff of 1 and causes a loss of 5 to the other side. ${ }^{15}$ They found that females are less likely to lie in such a situation and therefore are more altruistic than males. (This is in contrast to our findings which suggest that secular females are the least honest among the various groups.) Other studies, such as Eckel and Grossman (2001) and Solnick (2001), have demonstrated that females' degree of altruism is more sensitive to the experimental setting (e.g., face-to-face vs. total anonymity).

According to Croson and Gneezy (2009)'s review of gender differences in preferences, most studies have found that females are more risk averse, more altruistic and less competitive than males. Several studies, however, have shown that gender differences tend to disappear when individuals operate in a competitive environment. Johnson and Powel (1994) and Atkinson, Baird and Frye (2003) found evidence of a

\footnotetext{
${ }^{15}$ In Fischbacher and Föllmi-Heusi (2013)'s setting, the game is a symmetrical zero-sum game, where the choice of five or six gives rise to an additional payoff to the participant and an equivalent loss to the experimenter.
} 
similar degree of risk propensity between the genders among mutual fund managers and those studying to become mutual fund managers.

The results reported in the literature thus support our conclusion regarding the effect of a behavioral code on the level of honesty and opportunistic behavior. The Orthodox and ultra-Orthodox subjects in our experiment are preparing for a career in a competitive environment. Nevertheless, and even though they report lower income than the secular females, the reported outcomes of the religious subjects are found to be more honest. In other words, the indoctrination of values that prohibit lying offset the monetary incentive to lie and the effect of a competitive environment.

\section{Experimental Design}

We conduct a simplified version of Fischbacher and Föllmi-Heusi (2013)'s under-thecup die experiment. The participants in the experiment received a fair die and were asked to roll it once unobserved. The participants received a fixed payment for participating and a payment that increased with the reported outcome of the die throw. In Fischbacher and Föllmi-Heusi (2013)'s original baseline experiment, participants received an additional 1, 2, 3, 4 or 5 Swiss Francs for reporting the outcomes 1, 2, 3, 4 or 5 respectively and no additional payment for reporting 6 . In our simplified version, reported outcomes were multiplied by ten, so that the subjects received $10,20,30,40$, 50 or 60 NIS for reporting 1, 2, 3, 4, 5 or 6 respectively and an additional 20 NIS for participating. Thus, we have shifted the focus of interest to the reported outcomes of five and six (rather than 4 and 5 as in the original experiment).

The first experiment was carried out on Tuesday, December 4, 2012. We deliberately conducted the experiment in the middle of the week in order to avoid a potential bias arising from the fact that Orthodox and ultra-Orthodox Jews consider Saturday to be a holy day.

The participants were sampled from populations of secular, Orthodox and ultraOrthodox Jews, both male and female. The subjects were studying toward a BA or MA in Economics, Accounting or Business Administration at the College of Management in Rishon LeZion or the Jerusalem College of Technology (JCT). The College of Management is a regular college, whose students are mostly secular Jews. As in most Western universities or colleges, females and males study together there in mixed classes and the sole focus is on teaching material related to the student's chosen 
field of study. The students at JCT are all Orthodox or ultra-Orthodox Jews. The College maintains strict separation of the genders with geographically separate campuses for males and females. The campus for females is further divided into two institutes: one for Orthodox females and one for ultra-Orthodox females. In addition to the secular studies, JCT encourages and provides students with the opportunity to incorporate high-level religious studies within their curriculum. This and the separation of genders make the JCT particularly attractive for the religious population.

Formally, the experiment was conducted simultaneously at all of the campuses as follows: two days prior to the actual experiment, notices were posted on the various campuses. The notices stated only that participation is on a voluntary basis and that subjects would be paid for participating. At the beginning of the experiment, the participants entered the room one at a time and were informed that they would receive 20 NIS for participating. They then filled out a detailed and anonymous sociodemographic questionnaire. After completing the questionnaire, they were handed a sheet of instructions (see Appendix A). After verifying that they understood the instructions, the experimenter handed a die to the subject. The subject then entered a different room where the actual experiment would be carried out. In order to ensure that the subjects would be unobserved, the actual roll of the die was done behind a curtain. The participant then reported the outcome to the experimenter and handed him the filled-in questionnaire. The experimenter recorded the outcome on the questionnaire and handed the participant a voucher which was then exchanged for the actual payment. This concluded the experiment. ${ }^{16}$ The participant left the room through a different door in order to prevent any contact with subjects who had not yet rolled the die. It took approximately 15 minutes for each subject to complete the experiment (including filling out the questionnaire). ${ }^{17}$

\footnotetext{
${ }^{16}$ We made sure that participants did not know the experimenters by recruiting them from outside the College of Management and the JCT. In any case, Israeli students are usually unfamiliar with the activities and representatives of their student union (only 30\% of students entitled to vote for their student union representatives actually do so). Moreover, as Fischbacher and Föllmi-Heusi (2013) demonstrated, results were robust even when subjects did not report the outcome directly to the experimenter.

${ }^{17}$ We conducted the second and third experiments (which are described in sections 7 and 8) using the same methodology.
} 


\section{The first experiment: Description of the Data}

The data was collected by means of questionnaires filled in by the participants, which included various socio-demographic background variables (gender, age, number of children, marital status, religious denomination and after-tax monthly household income).

Table 1 displays the summary statistics for the first experiment by gender. Note that females report an average die-throwing outcome (DIE) of 4.22 while males report 4.20. Thus, without differentiating between religious denominations, the reported diethrowing outcomes are similar for both genders. The null hypothesis that the average outcome is equal to 3.5 for all subjects is clearly rejected at the $1 \%$ level. Nevertheless, the null hypotheses that the average reported outcomes are equal to five or six ("partial liars" or "complete liars") are also clearly rejected at the $1 \%$ level. ${ }^{18}$ Thus, for the subjects as a whole, the level of dishonesty among participants can be described as moderate.

Another approach to measuring the level of honesty is to calculate the proportion of participants who report five or six within each group. This is done by defining a variable (DIE56) that equals 1 for the choices five or six and 0 otherwise (DIE56). If the group consists of "honest" participants, this proportion is expected not to exceed the expected proportion of one-third. Fifty-three percent of female participants and $44 \%$ of males participants reported five or six which are significantly higher than onethird. Thus, for both genders, the hypothesis that the reported outcomes are honest is rejected. Nonetheless, while for the female group the null hypothesis is rejected at the $1 \%$ level, for the male group it is rejected only at the $5 \%$ level. Thus, the female subjects appear to be less honest than the male subjects.

Data on household income level is derived from the self-rankings of the subjects relative to the average after-tax monthly household income of 11,534 NIS. The selfranking is based on five categories: equal to the average income of 11,534 NIS, well below the average, below the average, above the average and well above the average. Given the general preference not to reveal one's income (particularly among the ultraOrthodox population), this ordinal formulation of the question enhanced the chances

\footnotetext{
${ }^{18}$ The $99 \%$ confidence intervals are given by $(3.79,4.64)$ for females and $(3.77,4.53)$ for males
} 
of cooperation. ${ }^{19}$ By comparing the wages reported by employees and their employers, Yitzhaki (1980) and Furman (2005) demonstrated that self-ranking provides a good proxy for the wage level.

The majority of participants ranked their household's income either as equal to the average income of 11,534 NIS (26.37\% of the females and $33.01 \%$ of the males) or above it (25.27\% of the females and $27.18 \%$ of the males), which together account for $51.64 \%$ of the females and $60.19 \%$ of the males. Given that the monetary incentive declines with level of income, this relatively high level of income is of particular importance.

The distribution of the participants according to religious denomination is as follows: of 97 females (108 males), 32\% (33\%) are secular (SECULAR), 28\% (39\%) are Orthodox (ORTHODOX) and $38 \%$ (27\%) are ultra-Orthodox (ULTRA_ORTHODOX). Thus, among females the largest group is the ultra-Orthodox (38\%) while among males it is the Orthodox (39\%).

With respect to age group, the female participants were on average much younger than the males: 23 vs. 30 years old $(A G E) .{ }^{20}$ Finally, $28 \%$ of the females were married (MARRIED), $61 \%$ were single (SINGLE) and $11 \%$ were divorced (DIVORCED); none were widows (WIDOWER). The equivalent figures for males are: $42 \%$ married (MARRIED), 41\% single (SINGLE), 16\% divorced (DIVORCED) and 1\% widowers (WIDOWER).

Only $10 \%$ of the females have at least one child, as compared to $38 \%$ of the males (CHILDREN). The average number of children among the females who do have children is 3 and among males about 4 (CHILDREN_NO).

< Insert Table 1 Here>

\footnotetext{
${ }^{19}$ Indeed, of the 205 participants, only 6 female participants and 5 male participants refused to answer this question

${ }^{20}$ The average Orthodox female starts her academic studies at a younger age than the average Orthodox male. This is because Orthodox (and ultra-Orthodox) females are not required to serve in the army, although they often serve for one or two years in voluntary "national service". The Orthodox male serves 3 years of mandatory army service (as does the secular male). The ultra-Orthodox male studies at a "yeshiva" at least until the age of 23 and in many cases begins his academic studies only after he is married, which explains why the males are relatively older in our sample.
} 


\section{The First Experiment: Methodology and Results}

\section{5a. The Model}

From a purely economic perspective, the monetary incentive to lie (and thus the level of dishonesty) is expected to decline at higher levels of household income. The opposite outcome (namely a higher level of honesty among the lower-income group) is paradoxical and may be explained by the adherence to behavioral codes based on religious commandments.

To test these hypotheses, we estimate a model consisting of the following (separate) equations: $^{21}$

(1) $R A N K_{-} I N C=\alpha_{1} A G E+\alpha_{2} O R T H O D O X \times A G E+\alpha_{3} U L T R A \_O R T H O D O X \times A G E+\alpha_{4}+\mu_{1}$

and

(2) $D I E=\beta \cdot F E M A L E S+\gamma \cdot M A L E S$

where:

(2a) $\beta=\beta_{1}+\beta_{2}$ ORTHODOX $+\beta_{3}$ ULTRA_ORTHODOX $+\beta_{4}(A G E-26.6)+\beta_{5}$ SINGLE + $\beta_{6}$ DIVORCED $+\beta_{7}$ CHILDREN

(2b) $\gamma=\gamma_{1}+\gamma_{2}$ ORTHODOX $+\gamma_{3} U L T R A_{-}$ORTHODOX $+\gamma_{4}(A G E-26.6)+\gamma_{5} S I N G L E+$ $\gamma_{6}$ DIVORCED $+\gamma_{7}$ CHILDREN

$R A N K \_I N C$ is the subject's self-ranking of income level on a scale of 1 (well below the average) to 5 (well above the average), ${ }^{22} D I E$ is the reported outcome of the die throw, FEMALE (MALE) equals 1 if the subject is a male (female) and 0 otherwise; ORTHODOX and ULTRA_ORTHODOX equals 1 if the participant is either Orthodox or ultra-Orthodox and 0 otherwise (the base category is SECULAR);AGE is age in years ${ }^{23}$ SINGLE and DIVORCED equal 1 if the subject is single or divorced and 0 otherwise; CHILDREN equals 1 if the subject has at least one child and 0 otherwise;

${ }^{21}$ We also tried to incorporate the income variable in the estimation of equation (2) but its coefficient was not significant. As we demonstrate below, the level of income is negatively correlated with the level of religiosity.

${ }^{22}$ We estimate an ordered probit regression where the dependent variable is the subject's self-ranking of household income. This methodology yields four constant terms (one for each of the two adjacent categories) and permits the estimation of projected probability for each category (see, for example, Greene, 2012: 827-831). In addition, we run both models separately for females and males.

${ }^{23}$ By defining the age variable as the difference between the subject's age and the mean age of the sample (26.6 years old), $\beta_{1}\left(\gamma_{1}\right)$ becomes the expected die-throwing outcome reported by a 26.6 yearold secular and married female (male) without children. 
$\alpha_{1}, \alpha_{2}, \alpha_{3}, \alpha_{4} ; \beta_{1}, \beta_{2}, \cdots, \beta_{7}$ and $\gamma_{1}, \gamma_{2}, \cdots, \gamma_{7}$ are parameters, $\alpha_{4}=\left[\alpha_{41}, \alpha_{42}, \alpha_{43}, \alpha_{44}\right],{ }^{24}$ and $\mu_{1}$ and $\mu_{2}$ are the classical random disturbance terms.

Estimation of equation (1) is designed to test the variation of the level of income across religious denominations and age groups. Estimation of equation (2) enables us to test for differences in the reported die-throwing outcomes according to degree of religiosity, age and gender.

\section{5b. Results: Self-Ranking of Income Level}

We first performed a specification test for the ordered probit regression. The parallel regression assumption states that unlike the constant terms, the coefficients of the explanatory variables are common to all income categories. To test the validity of this assumption, we used Brant's Wald test. Results support the conclusion that the parallel regression assumption is not violated. ${ }^{25}$

Table 2 displays the outcomes of the ordered probit regression and the expected probabilities for each category. As can be seen, Orthodox and ultra-Orthodox subjects ranked their household income significantly lower than secular subjects (at the $1 \%$ and 5\% levels). This outcome is also consistent with information obtained from the 2009 survey carried out by the Central Bureau of Statistics. According to Yitzhaki (1980) and Furman (2005), such surveys provide a good proxy for the wage level reported by employees to government authorities. According to the survey data, $78 \%$ of the ultra-Orthodox population lives in households with monthly per capita income of less than 2,000 NIS. The proportion is $48 \%$ for Orthodox households and $24 \%$ for secular ones.

With respect to age, table 2 shows that while the income ranking does not vary with age for secular subjects, it declines with age for Orthodox and ultra-Orthodox subjects (significant at the 5\% level). Thus, the income gap between secular households on the one hand and Orthodox and ultra-Orthodox households on the other increases with age. Some of this gap can be explained by lower workforce participation rates among the ultra-Orthodox population. Thus, according to the 2009 survey, $80-88 \%$ (93-94\%) of the secular and Orthodox female (male) population

\footnotetext{
${ }^{24}$ Recall, that since $R A N K_{-} I N C$ has five categories, the ordered probit regression yields four constants, one for each pair of adjacent categories.

${ }^{25}$ The calculated chi-square value with 9 degrees of freedom is 14.55 ; the calculated p-value is $10.4 \%$.
} 
participate in the workforce, i.e. are either employed or registered as job-seekers, in contrast to only $61 \%(52 \%)$ of the ultra-Orthodox population.

\section{<Insert Table 2 Here>}

The transformation of coefficients into projected probabilities yields similar results. In this case, the direction of change in projected probabilities according to age differs between the groups. The projected probability of secular subjects to report RANK=1 (the lowest income rank) declines from $12 \%$ for $\mathrm{AGE}=20$ to $7 \%$ for $\mathrm{AGE}=40$. In contrast, the projected probability of Orthodox (ultra-Orthodox) subjects to report RANK $=1$ increases with age from $21 \%$ (20\%) when $A G E=20$, to $25 \%$ (23\%) when $\mathrm{AGE}=40$. The opposite result is obtained for $\mathrm{RANK}=5$ (the highest income rank): The projected probability of secular subjects to report RANK=5 (the highest income rank) increases with age, from $10 \%$ for $\mathrm{AGE}=20$ to $16 \%$ for $\mathrm{AGE}=40$. The projected probability of Orthodox and ultra-Orthodox subjects to report RANK=5 remains unchanged at $4-5 \%$.

The results therefore indicate that stricter adherence to religious commandments is associated with lower income levels, which is line with the findings of Berman (2000) and the 2009 Central Bureau of Statistics survey. Moreover, these income gaps tend to widen in the older age groups. As demonstrated below, although the monetary incentive to lie increases with the level of religiosity, the level of dishonesty paradoxically decreases with the level of religiosity, which further emphasizes the effect of behavioral codes on the degree of honesty.

\section{5c. Results: Test of Honesty}

Table 3 displays the estimation results. The regression equation reported in Column (1)-(2) includes only dummies for the different religious groups (ORTHODOX and ULTRA_ORTHODOX where the base category is SECULAR) while Column (3)-(4) adds socio-demographic control variables (AGE, SINGLE, DIVORCED and CHILDREN). Columns (1) and (3) report the outcomes obtained for the full model, while Column (2) and (4) report only the significant coefficients. Thus, the average reported outcomes for secular females and males are 4.79 and 4.49, respectively (in the case of Column (1)) and 4.79 and 4.15, respectively (in the case of Column (2)). The reported outcome of secular females was significantly higher than that of 
Orthodox females (by 0.86-0.96 which is significant at the 5\% level) and of ultraOrthodox females (by 0.87-0.90 which is significant at the 5\% level). Finally, the reported outcome of secular males was significantly higher than that of ultraOrthodox males (by 0.77 which is significant at the $5 \%$ level), and the reported outcome declined with age at a rate of 0.04 per year (significant at the $1 \%$ level).

\section{<Insert Table 3 Here>}

Based on the regression results, table 4 displays the distribution of reported outcomes by gender and degree of religiosity. The reported die-throwing outcome for secular females (4.79) is significantly higher than the expected fair outcome (i.e. 3.5) at the $1 \%$ level. Moreover, we cannot reject the null hypothesis that their reported outcome is equal to five even at the $5 \%$ level. ${ }^{26}$ In contrast, we cannot reject the null hypothesis that the average die-throwing outcome reported by Orthodox and ultraOrthodox females equals the expected fair outcome (i.e. 3.5). Furthermore, the null hypothesis that the average reported outcome is equal to five is clearly rejected for these two groups. Therefore, we can characterize secular females as "partial liars" and the Orthodox and ultra-Orthodox females as "honest".

\section{<Insert Table 4 Here>}

With respect to males, the table indicates that the reported die-throwing outcome for secular males (4.49) is significantly higher than the expected fair outcome (i.e. 3.5) at the $1 \%$ level. Unlike secular females, however, the null hypothesis that the reported outcome is equal to five is rejected at the $5 \%$ level though not at the $1 \%$ level. ${ }^{27}$ Since the rejection of the null hypothesis is weaker for secular males than for secular females there is a greater probability that they have been classified incorrectly as "partial liars" rather than as "honest".

While the null hypothesis that the average die-throwing outcome reported by Orthodox males (4.14) equals the expected fair outcome (i.e. 3.5) is rejected at the 5\% level, this is not the case for ultra-Orthodox males. On the other hand, the null

\footnotetext{
${ }^{26}$ Note, however, that even in this group, the null hypothesis that the average reported outcome is six is clearly rejected. This result is in line with Fischbacher and Föllmi-Heusi (2013).

${ }^{27}$ Ibid.
} 
hypothesis that the average reported outcome is equal to five is clearly rejected for both groups at the $1 \%$ level. Thus, the classification of Orthodox males is somewhere between "partial liars" and "honest" (and there is a higher probability that they have been incorrectly classified as "partial liars" rather than as "honest" than for secular males) while ultra-Orthodox males can be characterized as "honest" with greater confidence.

These classifications receive further support when we examine the differences between the reported outcomes. The differences between secular and Orthodox females (0.86) and between secular and ultra-Orthodox females (0.87) are significant at the 5\% level. The difference between secular and ultra-Orthodox males (0.76) is significant at the 5\% level. Results of the Kolmogorov-Smirnov (hereinafter K-S) test indicate that the maximum difference in the cumulative reported frequencies between Orthodox and secular females is significantly different at the $10 \%$ level and between ultra-Orthodox and secular females at the 5\% level. Note that the differences between the reported outcomes of the Orthodox and ultra-Orthodox subjects were found to be insignificant.

With respect to differences between the genders, we find that the average outcome reported by secular females (4.79) is higher than that reported by secular (4.49), Orthodox (4.14) or ultra-Orthodox males (3.72). The difference between secular females and Orthodox males (0.65) is also significant at the $10 \%$ level while that between secular females and ultra-Orthodox males (1.07) is significant at the 5\% level. $^{28}$

Figures 1A-1C illustrate the classification of the groups according to the distribution of the reported outcomes by gender and level of religiosity. For the secular and Orthodox groups, the relative frequencies of five and six exceed $\frac{1}{6}$ (the probability in a fair die throw). Table 4D shows the frequency of the outcomes of five and six among secular females (73\%), among secular males (51\%), among Orthodox females and males (48\%) and among ultra-Orthodox females (38\%) and males (31\%).

\footnotetext{
${ }^{28}$ Due to space limitations, the tables of cross-differences are not presented. They are available upon request.
} 
Note that the frequency for secular females (73\%) is significantly higher than any other reported for groups within the sample. ${ }^{29}$ Among the secular groups, we reject the null hypothesis that the relative frequency of the outcomes five and six equals one-third $\left(\frac{1}{6}+\frac{1}{6}\right)$ at the $1 \%$ level for females and at the $5 \%$ level for males. Finally, note the low frequencies (38\% and 31\%) and the high variance (99\% confidence interval of $(0.17,0.58)$ for females and $(0.09,0.53)$ for males) among the ultraOrthodox groups, which implies that responses in this group were non-homogeneous.

\section{<Insert Figures 1A-1C Here>}

Column 4 in Table 3 shows that the reported outcome of males declines by 0.04 per year (the only significant coefficient for males at the $1 \%$ level). In other words, the reported outcome of males is explained by age rather than degree of religiosity. On the other hand, the tables in Appendix $\mathrm{C}$ show that the secular males are on average younger than the ultra-Orthodox males (28.24 versus 32.66, where the 4.42 difference is statistically significant at the $5 \%$ level). In order to further emphasize the difference between 26.6 year-old females (the sample mean) and ultra-Orthodox males, we present the reported outcomes of males by age in Table $5 .^{30}$

\section{$<$ Insert Table 5 Here>}

The analysis reveals that the reported outcomes of males decline with age from 4.57 (for 20 year-old males) to 3.53 (for 45 year-old males). Together with the results for the older ultra-Orthodox age group, this finding provides further support for the correlation between religiosity and the level of honesty among males. The respective reports of the 30 and 35 year-old males (the sample mean of the ultra-Orthodox male

\footnotetext{
${ }^{29}$ Owing to space limitations, these results are not included in the tables. The results are as follows. The difference of $22 \%$ between secular females and secular males (73\% vs. $51 \%)$ is significant at the $10 \%$ level. The difference of $25 \%$ between secular and Orthodox females (73\% vs. $48 \%$ ) is significant at the $10 \%$ level. The difference of $25 \%$ between secular females (73\%) and Orthodox males (48\%) is significant at the $5 \%$ level. The difference of $35 \%$ between secular and ultra-Orthodox females $(73 \%$ vs. $38 \%$ ) is significant at the $1 \%$ level. Finally, the difference of $42 \%$ between secular females (73\%) and ultra-Orthodox males $(31 \%)$ is significant at the $1 \%$ level.

${ }^{30}$ Note that the estimated age coefficient is not significantly different from zero for females. Consequently, the results apply to females aged 26.6, which is the sample mean.
} 
group) are 4.15 and 3.95 , which are significantly higher than the fair die expectancy (3.5), but significantly different from five even at the $1 \%$ level. These reports are still higher than the average female reported outcome (3.89), although the difference is statistically insignificant. The null hypothesis that the reported outcome equals 3.5 cannot be rejected only for the 40-45 age group and therefore older males can be classified as "honest". This heterogeneity of reported outcomes indicates that the reported outcomes of the ultra-Orthodox subjects do not reflect blind obedience to religious commandments and further emphasizes the role of education in instilling values of honesty.

Note the higher level of honesty among the ultra-Orthodox group, despite the decline in income level with age among ultra-Orthodox males. Consequently, we can classify them as more honest than secular males due to the greater incentive they have to report higher outcomes. This last result further stresses the effect of the indoctrination of norms of honesty since older males, and especially older ultraOrthodox males, have been indoctrinated to internalize religious values for a longer period than young religious or secular males.

In sum, although self-ranked household income is negatively correlated with the degree of religiosity, the level of honesty increases with the degree of religiosity, suggesting that greater obedience to behavioral codes more than compensates for the decline in income and the resulting increase in the incentive to lie. At the other extreme, secular females are found to have the lowest level of honesty among the groups.

\section{The second experiment: The Effect of a Monetary Incentive}

The findings of the first experiment indicate a higher level of honesty among the religious groups than among the secular group. In order to establish a clear linkage between the monetary incentive to lie and the level of honesty among the secular group, we conducted a control experiment. The experiment was conducted among first year students at the College of Management on Wednesday, October 23, 2013 (one year after the first experiment). It was identical to the original experiment, except for the elimination of the monetary incentive to lie. Participants were paid a fixed amount of 55 NIS for participating regardless of their reported outcome (instructions for the control experiment are given in Appendix B). 
Participating in the control experiment were 77 students ( 37 females and 40 males) who all classified themselves as secular. As can be seen from the tables in Appendix $\mathrm{D}$, the male participants in the second experiment are younger than those in the first (25.97 versus 28.24$)$. The positive correlation between the level of honesty and age among males improves the quality of the control group. In contrast, the females in the two experiments were of a similar age (sample mean of 24).

The results of the second experiment are reported in Table 6 and Figures 2A-2B. In order to emphasize the difference in reported outcomes between the two different incentive structures, the samples of the first and second experiments were pooled. The secular control group (without an incentive to lie) constitutes the base category in the estimation.

\section{< Insert Table 6 Here>}

The results clearly demonstrate that in the absence of a monetary incentive to lie, the distribution of reported outcomes is quite similar to the expected fair die-throwing outcome for all groups. The average reported outcome is 3.49 for females and 3.60 for males. Unlike in the first experiment, we cannot reject the null hypothesis for either gender that the average reported outcome equals the fair expected outcome (3.5), while the hypothesis that the average reported outcome equals five is rejected. Moreover, for both the treatment and control female groups (with and without an incentive to lie), the K-S test shows a significantly different distribution of reported outcomes at the $1 \%$ level.

The results show that in the presence of an incentive to lie, the reported outcomes of secular females increase by 1.30 (significant at the $1 \%$ level) and those of secular males increase by 0.89 (significant at the 5\% level) in comparison to the secular control group (which did not have an incentive to lie). This result is obtained even though the secular males in the treatment group (who have an incentive to lie) are older than the control group and the income levels of both genders in the treatment and control groups are the same. ${ }^{31}$ Moreover, no significant difference in reported

\footnotetext{
${ }^{31}$ The results of the ordered-probit regression are available upon request. The null hypothesis of the same income level is rejected for males at the $10 \%$ level, but is not rejected at the $5 \%$ level. For females, the null hypothesis is clearly supported (calculated $p$-value of 0.38 )
} 
outcomes is found between the secular control group (which does not have an incentive to lie) and the Orthodox and ultra-Orthodox groups.

\section{< Insert Table 7 Here>}

According to the findings in Table 7, 30\% of the secular females and 35\% of the secular males reported five or six (as compared to $73 \%$ of the secular females and $51 \%$ of the secular males in the first experiment). We cannot reject the null hypothesis that the frequency of the reported outcomes of the control group (which does not have an incentive to lie) is equal to the expected outcome of a fair die-throw (i.e. one-third). Furthermore, the 5\% difference between genders is not statistically significant.

\section{$<$ Insert figures 2A-2B Here >}

In sum, the results of both experiments indicate that subjects who chose to report five or six in the first experiment were responding to the monetary incentive to lie. Their strategy thus appears to be more influenced by maximization of personal monetary gain rather than by behavioral codes and in the absence of a monetary incentive to lie they indeed reported honestly.

\section{The third experiment: Test of Robustness}

In view of the long interval between the first and second experiments and the physical separation between the religious and secular academic institutions, we replicated the two previous experiments among students at the Carmel Academic Center (on Tuesday, November 12, 2013) in order to test the robustness of the findings. ${ }^{32}$ The Carmel Academic Center offers degrees in Business Administration and Accounting and its students are divided between secular, Orthodox and ultra-Orthodox. ${ }^{33}$ In this replication of the experiment, we randomly assigned the fixed and increasing

\footnotetext{
${ }^{32}$ At this point, we would like to thank Robert Aumann for his recommendation to replicate the experiment at other academic institutions.

${ }^{33}$ Nonetheless, there are separate classes for ultra-Orthodox students in which the genders are separated. Unlike in the previous experiments, both secular and ultra-Orthodox classes are taught on the same campus.
} 
monetary payoffs among the secular participants. We also verified that the payoff expectancy is equal across different incentive structures. ${ }^{34}$ Prior to the actual die throwing, all participants filled in the same socio-demographic background questionnaires as in the previous experiments.

Appendix E describes the various groups of subjects in the third experiment. A total of 253 students participated in the third experiment, where the treatment groups (which had a monetary incentive to lie) included 194 participants and the control group (which did not have a monetary incentive to lie) included 59 participants. The gender distribution in the third experiment is 129 females and 124 males. A comparison of the treatment group to the subjects in the first experiment shows that the secular females are approximately the same age (24.73 as compared to 24.21); ultra-Orthodox females are older (25.63 as compared to 21.04) and the ultra-Orthodox males are younger (26 as compared to 32.66 ) as are the secular males (25.45 as compared to 28.24). As can be seen in Appendix E, the age variable in the third experiment is not significantly different for the secular and ultra-Orthodox treatment groups. The average age of secular females (males) who were given an incentive to lie is 24.73 (25.45), while for ultra-Orthodox females (males) it is 25.45 (26.00). Likewise, the difference between the average ages of secular and Orthodox females is not statistically significant (24.73 as compared to 26.24$)$. Thus, in comparison to the first experiment, the age variable is better controlled for in the case of the secular and ultra-Orthodox treatment groups.

With respect to the income variable, the results of the ordered probit regression (available upon request) are similar to those obtained in the first experiment. They reveal the same tendency of Orthodox and ultra-Orthodox females and males to rank their household income significantly lower (at the $1 \%$ level) than secular females and males. On the other hand, no significant difference in income ranking was found between secular females and males in the treatment group and in the control group.

Table 8 presents the regressions analysis of the reported outcomes, where the base category is the control group of secular females and males (which did not have a

\footnotetext{
${ }^{34}$ The subjects received a fee of 55 NIS in the case that they were assigned to the fixed payoff group. In the case that they were assigned to the increasing monetary incentive group, they received a payment of 20 NIS for participating in addition to 10 NIS, 20 NIS, 30 NIS, 40 NIS, 50 NIS or 60 NIS if their report was one, two, three, four, five or six respectively. Thus, under the second alternative, the expected payoff also equals 55 NIS (20 NIS plus 35 NIS $=\frac{1}{6} \times[1+2+3+4+5+6] \times 10$ NIS for honest individuals).
} 
monetary incentive to lie). The results were found to be similar to those of the previous two experiments. The average reported outcome for secular participants who did not have a monetary incentive to lie is 3.68 for females and 3.32 for males. As can be seen from Table 9, the null hypothesis that the reported outcomes are equal to the expected fair die throw outcome (3.5) is not rejected at the $5 \%$ level for either gender. Moreover, the hypotheses that they are equal to five or six are rejected even at the $1 \%$ level. On the other hand, when secular participants are given a monetary incentive to lie, their reported outcome rises by 1.50 for females and by 1.25 for males, which are significant at the $1 \%$ level. Thus, the random assignment of incentives to secular participants with the same income level strengthens the conclusion that the monetary incentive to lie encourages them to report five or six. Finally, note that in the absence of an incentive to lie, the difference between the reported outcomes between the secular group and the Orthodox group and between the secular group and the ultraOrthodox group is not statistically significant.

\section{< Insert Table 8 Here> \\ < Insert Table 9 Here>}

Table 9 compares the reported outcomes of the various treatment groups (which were given a monetary incentive to lie). Once again the lowest level of honesty is found among secular females, followed by secular males, and both can be characterized as "partial liars", even though their level of income is equal to that of the secular control groups and higher than that of the more religious treatment groups. The null hypotheses that the expected outcomes of the secular male and female subjects are equal to 3.5 or six are rejected at the $1 \%$ level, while the null hypothesis that they are equal to five is not. Moreover, the average report of secular females (5.18) is found to be significantly higher than that of the secular males (4.57) at the 5\% level. In contrast, Orthodox and ultra-Orthodox participants reported honestly, even though they have a stronger monetary incentive to lie (due to their lower levels of income), where the highest level of honesty is found among ultra-Orthodox females. The average reported outcomes of these groups ranges from 3.60 to 3.90 and the null hypothesis that they are equal to 3.5 cannot be rejected. On the other hand, the null hypothesis that they are equal to five or six is rejected at the $1 \%$ level. 
The characterization of the secular participants as "partial liars" is further supported by the K-S test. The results indicate that the maximum differences in the cumulative reported frequencies between Orthodox females and secular females and between ultra-Orthodox females and secular females are significantly different at the $1 \%$ level. The average reported outcome for secular females (5.18) is higher by 1.33 than that of Orthodox females and higher (by 1.58) than that of ultra-Orthodox females (significant at the $1 \%$ level). The average reported outcome of the secular males (4.57) is higher than that of the Orthodox males by 0.67 (significant at the $10 \%$ level) and higher than that of the ultra-Orthodox males by 0.67 (significant at the $5 \%$ level). Note also that the differences between the average reported outcomes of the Orthodox subjects and those of the ultra-Orthodox subjects were not found to be significant.

Figures 3A-3C present the distributions of the reported outcomes by gender and level of religiosity. It can be seen that the relative frequencies of five and six among the secular groups noticeably exceed the probability of $\frac{1}{6}$ (the frequency expected in a fair die throw).

\section{< Insert Figure 3A-3B Here>}

Table 9E reveals a higher tendency among Orthodox and ultra-Orthodox males to report five and six relative to Orthodox and ultra-Orthodox females. Note also the low frequencies (27\% for females and $42 \%$ for males) and the high variance (99\% confidence interval of $(0.04,0.49)$ for females and $(0.17,0.67)$ for males) among the ultra-Orthodox group. This implies a lack of homogeneity in the responses of this group and that they are not blindly following religious commandments.

The frequency of five and six among secular females (79\%) and secular males (55\%) in the treatment group (with an incentive to lie) is higher than one-third (significant at the $1 \%$ level for females and at the $5 \%$ level for males). Note that the frequency for secular females in the treatment group (79\%) is significantly higher than any other reported for groups within the sample. ${ }^{35}$

\footnotetext{
35 Once again, owing to space limitations, these results are not included in the tables. The results are as follows. The difference of $24 \%$ between secular females (79\%) and secular males (51\%) is significant at the $5 \%$ level. The difference of $43 \%$ between secular females in the treatment and control group (79\% vs. 36\%) is significant at the $1 \%$ level. The difference of $54 \%$ between secular females in the treatment group and secular males in the control group (79\% vs. $25 \%$ ) is significant at the $1 \%$ level. The difference of $41 \%$ between secular and Orthodox females (79\% vs. 38\%) is significant at the $1 \%$.
} 
Overall, the results of the third experiment strengthen the conclusions of the previous two and confirm their robustness, thus providing further evidence of the role of education in instilling values of honesty.

\section{Summary and Conclusions}

We conduct under-the-cup die experiments to determine the extent to which behavioral codes offset the effect of monetary incentives to lie. We differentiate between secular, Orthodox and ultra-Orthodox subjects who are studying in highly competitive academic environments in preparation for professional careers. The main difference between the groups is in their level of religiosity. The Orthodox and ultraOrthodox subjects attended religious schools which focus on the in-depth study of Jewish religious texts. They have thus been indoctrinated to follow religious commandments, which include the prohibition of lying. And indeed our results show that the degree of religiosity has a positive effect on the degree of honesty.

Unlike other studies in which females were found to be more honest than males, the results show that secular females have the lowest level of honesty among the various groups while the highest level is to be found among young religious females. In addition, when there is no monetary incentive to lie, secular females (and males) behave honestly, which implies that it is the presence of a monetary incentive that motivates secular females to act dishonestly.

Given the total separation between the secular and religious education systems from kindergarten through high school, the findings stress the importance of education in instilling ethical values. If the education system were used to instill behavioral codes of honesty in the general population and honesty became a social norm, then the costs incurred as a result of dishonesty, which include the cost of law enforcement and punishment, could be significantly reduced.

level. The difference of $32 \%$ between secular females (79\%) and Orthodox males (47\%) is significant at the $1 \%$ level. The difference of $41 \%$ between secular and ultra-Orthodox females (79\% vs. $38 \%)$ is significant at the $1 \%$ level. Finally, the difference of $47 \%$ between secular females $(79 \%)$ and ultraOrthodox males $(32 \%)$ is significant at the $1 \%$ level. 


\section{References}

Akerlof, George, A. 1970. "The Market for Lemons: Quality Uncertainty and the Market Mechanism" Quarterly Journal of Economics, 84(3): 488-500.

Atkinson, Stanley M., Samantha B. Baird, and Melissa B. Frye. 2003. "Do Female Mutual Fund Managers Manage Differently?" Journal of Financial Research, 26(1): $1-18$.

Aumann, Robert J. 1997. "Rationality and Bounded Rationality" Games and Economic Behavior, 21(1-2): 2-14.

Becker, Gary S. 1993. "Nobel Lecture: The Economic Way of Looking at Behavior" Journal of Political Economy, 101(3): 385-409.

Berman, Eli. 2000. "Sect, Subsidy, and Sacrifice: An Economist's View of UltraOrthodox Jews" Quarterly Journal of Economics, 115(3): 905-953.

Bertoni, Marco, Giorgio Brunello, and Lorenzo Rocco. 2013. "When the Cat is Near, the Mice Won't Play: The Effect of External Examiners in Italian Schools" Journal of Public Economics, 104: 65-77.

Bidner, Chris and Patrick Francois. 2011. "Cultivating Trust: Norms, Institutions and the Implications of Scale" Economic Journal, 121(555): 1097-1129.

Central Bureau of Statistics: Press Release. 2009. "Social Survey 2009: Religiosity in Israel - Characteristics of Different Groups.": 1-5.

Charness, Gary and Martin Dufwenberg. 2006. "Promises and Partnership" Econometrica, 74(6): 1579-1601.

Childs, Jason. 2012. "Gender Differences in Lying" Economics Letters, 114(2): 147149.

Croson, Rachel and Uri Gneezy. 2009. "Gender Differences in Preferences" Journal of Economic Literature, 47(2): 448-474.

Dreber, Anna and Magnus Johannesson. 2008. "Gender Differences in Deception" Economics Letters, 99(1): 197-199.

Eckel, Catherine C. and Philip J. Grossman. 2001. "Chivalry and Solidarity in Ultimatum Games" Economic inquiry, 39(2): 171-188.

Erat, Sanjiv and Uri Gneezy. 2012. "White Lies" Management Science, 58(4): 723733.

Fischbacher, Urs and Franziska Föllmi-Heusi. 2013. "Lies in Disguise--an Experimental Study on Cheating" Journal of the European Economic Association, 11(3): 525-547. 
Furman, Orly. 2005. "Comparative Analysis of Wages and Work Indicators from Income Tax Records of wage Earners." Central Bureau of Statistics, Chief Scientist Office: 1-23 (Hebrew)

Gino, Francesca and Dan Ariely. 2012. "The Dark Side of Creativity: Original Thinkers can be More Dishonest." Journal of personality and social psychology, 102(3): 445.

Gneezy, Uri. 2005. "Deception: The Role of Consequences" American Economic Review, 95(1): 384-394.

Greene, William. H. 2012. Econometric Analysis (Seventh Edition) -International Edition. New York University.

Gylfason, Haukur F., Audur A. Arnardottir, and Kari Kristinsson. 2013. "More on Gender Differences in Lying" Economics Letters, 119(1): 94-96.

Hauk, Esther and Maria Saez-Marti. 2002. "On the Cultural Transmission of Corruption" Journal of Economic Theory, 107(2): 311-335.

Houser, Daniel, Stefan Vetter, and Joachim Winter. 2012. "Fairness and Cheating" European Economic Review, 56(8): 1645-1655.

Johnson, Johnnie E. and Philip L. Powell. 1994. "Decision Making, Risk and Gender: Are Managers Different?" British Journal of Management, 5(2): 123-138.

Kant, Immanuel. 1787. "On a Supposed Right to Lie from Benevolent Motives." in Lewis W. Beck, ed., The critique of practical reason and other writings in moral philosophy. Chicago: University of Chicago Press, 1949: 346-350.

Lundquist, Tobias, Tore Ellingsen, Erik Gribbe, and Magnus Johannesson. 2009. "The Aversion to Lying" Journal of Economic Behavior and Organization, 70(1-2): 81-92.

Mazar, Nina, On Amir, and Dan Ariely. 2008. "The Dishonesty of Honest People: A Theory of Self-Concept Maintenance" Journal of Marketing Research, 45(6): 633644.

Mazar, Nina and Dan Ariely. 2006. "Dishonesty in Everyday Life and its Policy Implications" Journal of Public Policy \& Marketing: 117-126.

Pruckner, Gerald J. and Rupert Sausgruber. 2013. "Honesty on the Streets: A Field Study on Newspaper Purchasing" Journal of the European Economic Association, 11(3): 661-679.

Shalvi, Shaul, Jason Dana, Michel J. Handgraaf, and Carsten K. De Dreu. 2011. "Justified Ethicality: Observing Desired Counterfactuals Modifies Ethical Perceptions and Behavior" Organizational behavior and human decision processes, 115(2): 181190. 
Shalvi, Shaul, Ori Eldar, and Yoella Bereby-Meyer. 2012. "Honesty Requires Time (and Lack of Justifications)" Psychological science, 23(10): 1264-1270.

Shalvi, Shaul and David Leiser. 2013. "Moral Firmness" Journal of Economic Behavior \& Organization. 93:400-407.

Shapiro, Carl and Joseph E. Stiglitz. 1984. "Equilibrium Unemployment as a Worker Discipline Device" The American Economic Review, 74(3): 433-444.

Solnick, Sara J. 2001. "Gender Differences in the Ultimatum Game" Economic inquiry, 39(2): 189-200.

Smith, Adam. 1759. The theory of moral sentiments. New Edition by Penguin 2010.

Weiss, Brent and Robert S. Feldman. 2006. "Looking Good and Lying to do it: Deception as an Impression Management Strategy in Job Interviews" Journal of Applied Social Psychology, 36(4): 1070-1086.

Witt, Ulrich. 2008. "Evolutionary Economics." in The New Palgrave Dictionary of Economics. Second Edition. Eds. Steven N. Durlauf and Lawrence E. Blume. Palgrave Macmillan.

Yitzhaki , Shlomo. 1980. "On the Gap between Wage for Employee and Wage for Employee's Job." Unpublished (Hebrew). 
Table 1: Summary Statistics - First Experiment

\begin{tabular}{|c|c|c|c|}
\hline Variable & Definition & Females & Males \\
\hline$\overline{D I E}$ & $\begin{array}{l}\text { Reported outcomes of die throwing }(1,2,3 \text {, } \\
4,5,6)\end{array}$ & $4.22^{\# \# \#}$ & $4.20^{\# \# \#}$ \\
\hline DIE56 & $\begin{array}{l}1 \text { - reported five or six } \\
0 \text { - otherwise }\end{array}$ & $0.53^{+++}$ & $0.44^{++}$ \\
\hline$R A N K \_I N C=1$ & $\begin{array}{l}\text { 1- self-ranking of well below the after-tax } \\
\text { average monthly household income of } \\
11,534 \text { NIS } \\
0 \text { - otherwise }\end{array}$ & $24.18 \%$ & $11.65 \%$ \\
\hline$R A N K \_I N C=2$ & $\begin{array}{l}\text { 1- self-ranking of below the after-tax } \\
\text { average monthly household income of } \\
11,534 \text { NIS } \\
0-\text { otherwise }\end{array}$ & $14.29 \%$ & $23.30 \%$ \\
\hline$R A N K \_I N C=3$ & $\begin{array}{l}1 \text { - self-ranking of equal to the after-tax } \\
\text { average monthly household income of } \\
11,534 \text { NIS } \\
0-\text { otherwise }\end{array}$ & $26.37 \%$ & $33.01 \%$ \\
\hline$R A N K \_I N C=4$ & $\begin{array}{l}\text { 1- self-ranking of above the after-tax } \\
\text { average monthly household income of } \\
11,534 \text { NIS } \\
0-\text { otherwise }\end{array}$ & $25.27 \%$ & $27.18 \%$ \\
\hline$R A N K \_I N C=5$ & $\begin{array}{l}\text { 1- self-ranking of well above the after-tax } \\
\text { average monthly household income of } \\
11,534 \text { NIS } \\
0 \text { - otherwise }\end{array}$ & $9.89 \%$ & $4.85 \%$ \\
\hline SECULAR & $\begin{array}{l}1 \text { - Secular } \\
0 \text { - otherwise }\end{array}$ & 0.32 & 0.33 \\
\hline RELIGIOUS_ORTHODOX & $\begin{array}{l}1 \text { - Orthodox } \\
0 \text { - otherwise }\end{array}$ & 0.28 & 0.39 \\
\hline ULTRA_ORTHODOX & $\begin{array}{l}1 \text { - Ultra-Orthodox } \\
0 \text { - otherwise }\end{array}$ & 0.38 & 0.27 \\
\hline$A G E$ & Age & 22.70 & 30.10 \\
\hline MARRIED & $\begin{array}{l}1 \text { - married } \\
0 \text { - otherwise }\end{array}$ & 0.28 & 0.42 \\
\hline SINGLE & $\begin{array}{l}1 \text { - single } \\
0 \text { - otherwise }\end{array}$ & 0.61 & 0.41 \\
\hline DIVORCED & $\begin{array}{l}1 \text { - divorced } \\
0 \text { - otherwise }\end{array}$ & 0.11 & 0.16 \\
\hline WIDOWER & $\begin{array}{l}1 \text { - widower } \\
0 \text { - otherwise }\end{array}$ & 0.00 & 0.01 \\
\hline CHILDREN & $\begin{array}{l}1 \text { - has at least one child } \\
0 \text { - otherwise }\end{array}$ & 0.10 & 0.38 \\
\hline CHILDREN_NO & $\begin{array}{l}\text { Number of children (for the } 51 \text { subjects } \\
\text { who have children) }\end{array}$ & 3 & 4.22 \\
\hline \multicolumn{2}{|l|}{ Number of subjects } & 97 & 108 \\
\hline \multicolumn{2}{|c|}{ Number of subjects who reported their level of household income } & 91 & 103 \\
\hline
\end{tabular}

Notes: The experiment was carried out simultaneously at the College of Management (a secular academic institution), and the Jerusalem College of Technology (a religious academic institution) on Tuesday, December 4, 2012. See Appendix A for the instructions given to the participants.. \#\# significantly greater than 3.5 (the expected outcome in a fair die throw) at the 5\% level.."\# significantly greater than 3.5 (the expected outcome in a fair die throw) at the $1 \%$ level. ${ }^{++}$significantly different from one-third (the expected frequency of the outcomes five (1/6) or six (1/6) in a single fair die throw) at the $5 \%$ level. ${ }^{+++}$significantly different from one-third (the expected frequency of the outcomes five $(1 / 6)$ or six (1/6) in a single fair die throw) at the $1 \%$ level. 
Table 2: Self-Ranked Level of Household Income

\begin{tabular}{|c|c|c|c|c|}
\hline VARIABLES & Coef. & $\begin{array}{c}(1) \\
\text { POOLED }\end{array}$ & $\begin{array}{c}\text { (2) } \\
\text { FEMALES }\end{array}$ & $\begin{array}{c}(3) \\
\text { MALES }\end{array}$ \\
\hline$A G E$ & $\alpha_{1}$ & $\begin{array}{c}0.01 \\
(0.01)\end{array}$ & $\begin{array}{l}-0.03 \\
(0.05)\end{array}$ & $\begin{array}{c}0.01 \\
(0.01)\end{array}$ \\
\hline ORTHODOX $\times A G E$ & $\alpha_{2}$ & $\begin{array}{c}-0.02 * * * \\
(0.01)\end{array}$ & $\begin{array}{c}-0.04 * * * \\
(0.01)\end{array}$ & $\begin{array}{l}-0.02 * \\
(0.01)\end{array}$ \\
\hline ULTRA_ORTHODOX $\times A G E$ & $\alpha_{3}$ & $\begin{array}{c}-0.02 * * \\
(0.01)\end{array}$ & $\begin{array}{l}-0.03 * \\
(0.01)\end{array}$ & $\begin{array}{l}-0.02 * \\
(0.01)\end{array}$ \\
\hline Constant 1 & $\alpha_{41}$ & $\begin{array}{c}-0.95 * * * \\
(0.26)\end{array}$ & $\begin{array}{l}-1.79 \\
(1.18)\end{array}$ & $\begin{array}{c}-1.25 * * * \\
(0.35)\end{array}$ \\
\hline Constant 2 & $\alpha_{42}$ & $\begin{array}{l}-0.33 \\
(0.25)\end{array}$ & $\begin{array}{l}-1.35 \\
(1.18)\end{array}$ & $\begin{array}{l}-0.42 \\
(0.33)\end{array}$ \\
\hline Constant 3 & $\alpha_{43}$ & $\begin{array}{l}0.46^{*} \\
(0.25)\end{array}$ & $\begin{array}{l}-0.65 \\
(1.17)\end{array}$ & $\begin{array}{c}0.46 \\
(0.33)\end{array}$ \\
\hline Constant4 & $\alpha_{44}$ & $\begin{array}{c}1.52 * * * \\
(0.27)\end{array}$ & $\begin{array}{c}0.29 \\
(1.18)\end{array}$ & $\begin{array}{c}1.68 * * * \\
(0.37)\end{array}$ \\
\hline $\begin{array}{l}\text { Observations } \\
\text { log likelihood }\end{array}$ & & $\begin{array}{c}194 \\
-290.2 \\
\end{array}$ & $\begin{array}{c}91 \\
-136.8 \\
\end{array}$ & $\begin{array}{c}103 \\
-147.5 \\
\end{array}$ \\
\hline
\end{tabular}

Notes: Estimation results using the ordered probit regression method. There are four constant terms: one for each pair of adjacent categories. The dependent variable is the subject's self-ranked level of household income (RANK_INC) on a scale of 1 to 5, where 1 is well below the average before-tax monthly household income of NIS 11,354 (which was provided to the participants in the questionnaire), 5 is well above the average and 3 is equal to the average. Subjects who did not rank their household income were excluded from the sample.

A preliminary specification test was carried out for the ordered probit regression. The parallel regression assumption states that, unlike the constant terms, the coefficients of the explanatory variables $\left(\alpha_{1}, \alpha_{2}, \alpha_{3}\right)$ are common to all income categories. Brant's Wald test was used to test the validity of the assumption. The results support the conclusion that the parallel regression assumption is not violated (calculated chi-square value of 14.55 with 9 degrees of freedom and p-value of $10.4 \%$ ). Standard errors appear in parentheses. * significant at the $10 \%$ level. ** significant at the $5 \%$ level. *** significant at the $1 \%$ level.

Following are the projected probabilities of choosing each income ranking for age $=20$ and age $=40$ based on the ordered probit regression coefficients:

\begin{tabular}{|c|c|c|c|c|c|}
\hline \multicolumn{6}{|l|}{$\mathrm{AGE}=20$} \\
\hline Group & Prob. $(R A N K=1)$ & Prob. $(R A N K=2)$ & Prob. $(R A N K=3)$ & Prob. $(R A N K=4)$ & Prob. $(R A N K=5)$ \\
\hline SECULAR & $12 \%$ & $16 \%$ & $30 \%$ & $32 \%$ & $10 \%$ \\
\hline ORTHODOX & $21 \%$ & $21 \%$ & $30 \%$ & $23 \%$ & $5 \%$ \\
\hline ULTRA_ORTHODOX & $20 \%$ & $21 \%$ & $30 \%$ & $24 \%$ & $5 \%$ \\
\hline \multicolumn{6}{|l|}{$\underline{\mathrm{AGE}=40}$} \\
\hline Group & Prob. $(R A N K=1)$ & Prob. $(R A N K=2)$ & Prob. $(R A N K=3)$ & Prob. $(R A N K=4)$ & Prob. $(R A N K=5)$ \\
\hline SECULAR & $7 \%$ & $13 \%$ & $28 \%$ & $36 \%$ & $16 \%$ \\
\hline ORTHODOX & $25 \%$ & $23 \%$ & $29 \%$ & $20 \%$ & $4 \%$ \\
\hline ULTRA_ORTHODOX & $23 \%$ & $22 \%$ & $30 \%$ & $21 \%$ & $4 \%$ \\
\hline
\end{tabular}


Table 3: Reported Outcomes with a Monetary Incentive to Lie

\begin{tabular}{|c|c|c|c|c|c|}
\hline & & $(1)$ & (2) & (3) & (4) \\
\hline Model & & Full & Step-wise & Full & Step-wise \\
\hline VARIABLES & Coef. & DIE & DIE & DIE & DIE \\
\hline FEMALE & $\beta_{1}$ & $\begin{array}{c}4.79 * * * \\
(0.26)\end{array}$ & $\begin{array}{c}4.79 * * * \\
(0.27)\end{array}$ & $\begin{array}{c}4.68^{* * * *} \\
(0.35)\end{array}$ & $\begin{array}{c}4.79 * * * \\
(0.26)\end{array}$ \\
\hline FEMALE $\times$ ORTODOX & $\beta_{2}$ & $\begin{array}{c}-0.86^{* *} \\
(0.39)\end{array}$ & $\begin{array}{c}-0.86^{* *} \\
(0.40)\end{array}$ & $\begin{array}{c}-0.96^{* *} \\
(0.43)\end{array}$ & $\begin{array}{l}-0.91 * * \\
(0.40)\end{array}$ \\
\hline FEMALE $\times$ ULTRA_ORTHODOX & $\beta_{3}$ & $\begin{array}{c}-0.87 * * \\
(0.36)\end{array}$ & $\begin{array}{c}-0.87 * * \\
(0.37)\end{array}$ & $\begin{array}{l}-0.90^{*} \\
(0.47)\end{array}$ & $\begin{array}{l}-0.90^{* *} \\
(0.36)\end{array}$ \\
\hline$F E M A L E \times(A G E-26.6)$ & $\beta_{4}$ & - & - & $\begin{array}{c}0.02 \\
(0.06)\end{array}$ & - \\
\hline$F E M A L E \times$ SINGLE & & - & $\begin{array}{l}- \\
-\end{array}$ & $\begin{array}{c}0.32 \\
(0.40)\end{array}$ & $\begin{array}{l}- \\
-\end{array}$ \\
\hline FEMALE $\times$ DIVORCED & & $\begin{array}{l}- \\
-\end{array}$ & $\begin{array}{l}- \\
-\end{array}$ & $\begin{array}{l}-0.07 \\
(0.56)\end{array}$ & $\begin{array}{l}- \\
-\end{array}$ \\
\hline FEMALE $\times$ CHILDREN & & - & - & $\begin{array}{c}0.12 \\
(0.67)\end{array}$ & $\begin{array}{l}- \\
-\end{array}$ \\
\hline MALE & $\gamma_{1}$ & $\begin{array}{c}4.49 * * * \\
(0.25)\end{array}$ & $\begin{array}{c}4.15 * * * \\
(0.15)\end{array}$ & $\begin{array}{c}4.99 * * * \\
(0.38)\end{array}$ & $\begin{array}{c}4.31^{* * * *} \\
(0.15)\end{array}$ \\
\hline MALE $\times$ ORTHODOX & $\gamma_{2}$ & $\begin{array}{l}-0.34 \\
(0.34)\end{array}$ & - & $\begin{array}{l}-0.29 \\
(0.36)\end{array}$ & - \\
\hline MALE $\times$ ULTRA_ORTHODOX & $\gamma_{3}$ & $\begin{array}{c}-0.77^{* * *} \\
(0.38)\end{array}$ & - & $\begin{array}{l}-0.62 \\
(0.40)\end{array}$ & - \\
\hline$M A L E \times(A G E-26.6)$ & $\gamma_{4}$ & - & - & $\begin{array}{c}-0.04 * * \\
(0.02)\end{array}$ & $\begin{array}{c}-0.04 * * * \\
(0.01)\end{array}$ \\
\hline$M A L E \times S I N G L E$ & & - & - & $\begin{array}{l}-0.63 \\
(0.42)\end{array}$ & $\begin{array}{l}- \\
-\end{array}$ \\
\hline$M A L E \times D I V O R C E D$ & & - & - & $\begin{array}{l}-0.08 \\
(0.49)\end{array}$ & - \\
\hline$M A L E \times C H I L D R E N$ & & $\begin{array}{l}- \\
-\end{array}$ & $\begin{array}{l}- \\
-\end{array}$ & $\begin{array}{l}-0.35 \\
(0.48)\end{array}$ & $\begin{array}{l}- \\
- \\
\end{array}$ \\
\hline Observations & & 205 & 205 & 201 & 201 \\
\hline $\begin{array}{l}\text { R-squared } \\
\text { log likelihood }\end{array}$ & & $\begin{array}{c}0.89 \\
-373.3\end{array}$ & $\begin{array}{c}0.88 \\
-375.4\end{array}$ & $\begin{array}{c}0.89 \\
-360.9\end{array}$ & $\begin{array}{c}0.89 \\
-364.0\end{array}$ \\
\hline
\end{tabular}

Notes: The table presents the results of the experiment carried out simultaneously at the College of Management (a secular academic institution), and the Jerusalem College of Technology (a religious academic institution) on Tuesday, December 4, 2012 The dependent variable is the reported outcome of throwing a fair die (1, 2, 3, 4, 5 or 6). FEMALE and MALE (the base categories) equal 1 for secular females and males respectively and 0 otherwise. ORTHODOX and ULTRA_ORTHODOX equal 1 for Orthodox and ultra-Orthodox subjects respectively and 0 otherwise. The age variable is measured in years where AGE $=26.6$ is the sample mean. In columns (2) and (4), only significant coefficients (at the $5 \%$ level) are presented. Columns (1) and (2) include only dummies for the different groups (i.e. ORTHODOX and ULTRA_ORTHODOX where the base category is SECULAR). Columns (3) and (4) also include socio-demographic control variables (AGE, SINGLE, DIVORCED and CHILDREN). * significantly different from zero at the $10 \%$ level. $* *$ significantly different from zero at the $5 \%$ level. $* * *$ significantly different from zero at the $1 \%$ level. 
Table 4: Reported Outcomes with a Monetary Incentive to Lie - Comparison by Level of Religiosity and Gender

A. Comparison between secular and Orthodox subjects:

\begin{tabular}{|l|c|c|c|c|}
\hline \multirow{2}{*}{ Religiosity } & Females & Males & Difference & K-S test \\
\hline Secular & $4.79^{\text {\#\#\# }}$ & $4.49^{\# \# \#}$ & 0.30 & $D=0.21$ \\
& {$[4.24,5.34]$} & {$[4.04,4.94]$} & {$[-0.39,0.99]$} & p-value $=0.34$ \\
& $(4.05,5.53)$ & $(3.88,5.09)$ & $(-0.62,1.22)$ & \\
\hline Orthodox & 3.93 & $4.14^{\text {\#\# }}$ & -0.21 & $D=0.10$ \\
& {$[3.31,4.55]$} & {$[3.65,4.64]$} & {$[-0.99,0.56]$} & p-value=0.99 \\
& $(3.09,4.76)$ & $(3.48,4.80)$ & $(-1.25,0.82)$ & - \\
\hline Difference & $0.86^{* *}$ & 0.35 & 0.51 & - \\
& {$[0.05,1.67]$} & {$[-0.32,1.01]$} & {$[-0.51,1.55]$} & - \\
& $(-0.22,1.94)$ & $(-0.54,1.22)$ & $(-0.84,1.88)$ & - \\
\hline K-S test & $D=0.31^{*}$ & $D=0.09$ & - & - \\
& p-value=0.09 & p-value=0.99 & - & - \\
\hline
\end{tabular}

B. Comparison between secular and ultra-Orthodox subjects:

\begin{tabular}{|c|c|c|c|c|}
\hline Religiosity & Females & Males & Difference & $\mathrm{K}-\mathrm{S}$ test \\
\hline Secular & $\begin{array}{c}4.79^{\# \# \#} \\
{[4.24,5.34]} \\
(4.11,5.47)\end{array}$ & $\begin{array}{c}4.49^{\# \# \#} \\
{[4.04,4.94]} \\
(3.88,4.09)\end{array}$ & $\begin{array}{c}0.30 \\
{[-0.39,0.99]} \\
(-0.62,1.22)\end{array}$ & $\begin{array}{c}D=0.21 \\
\text { p-value }=0.34\end{array}$ \\
\hline Ultra-Orthodox & $\begin{array}{c}3.92 \\
{[3.40,4.44]} \\
(3.22,4.61)\end{array}$ & $\begin{array}{c}3.72 \\
{[3.16,4.29]} \\
(2.96,4.49)\end{array}$ & $\begin{array}{c}0.20 \\
{[-0.56,0.95]} \\
(-0.81,1.20)\end{array}$ & $\begin{array}{c}D=0.10 \\
\text { p-value }=0.98\end{array}$ \\
\hline Difference & $\begin{array}{c}0.87 * * \\
{[0.13,1.61]} \\
(-0.12,1.86) \\
\end{array}$ & $\begin{array}{c}0.77 * * \\
{[0.06,1.46]} \\
(-0.17,1.69) \\
\end{array}$ & $\begin{array}{c}0.10 \\
{[-0.91,1.12]} \\
(-1.23,1.45)\end{array}$ & - \\
\hline $\mathrm{K}-\mathrm{S}$ test & $\begin{array}{c}D=0.35^{* *} \\
\text { p-value }=0.02\end{array}$ & $\begin{array}{c}D=0.26 \\
\text { p-value }=0.16\end{array}$ & $\begin{array}{l}- \\
-\end{array}$ & $\begin{array}{l}- \\
-\end{array}$ \\
\hline
\end{tabular}

C. Comparison between Orthodox and ultra-Orthodox subjects:

\begin{tabular}{|l|c|c|c|c|}
\hline Religiosity & Females & Males & Difference & K-S test \\
\hline Orthodox & 3.93 & $4.14^{\# \#}$ & -0.21 & $D=0.10$ \\
& {$[3.31,4.55]$} & {$[3.65,4.64]$} & {$[-0.99,0.56]$} & p-value=0.99 \\
& $(3.09,4.76)$ & $(3.48,4.80)$ & $(-1.25,0.82)$ & \\
\hline Ultra-Orthodox & 3.92 & 3.72 & 0.20 & $D=0.10$ \\
& {$[3.40,4.44]$} & {$[3.16,4.29]$} & {$[-0.56,0.95]$} & p-value=0.98 \\
& $(3.22,4.61)$ & $(2.96,4.49)$ & $(-0.81,1.20)$ & - \\
\hline Difference & 0.01 & 0.42 & -0.41 & - \\
& {$[-0.77,0.78]$} & {$[-0.32,1.16]$} & {$[-1.49,0.66]$} & - \\
& $(-1.02,1.03)$ & $(-0.56,1.40)$ & $(-1.83,1.01)$ & - \\
\hline K-S test & $D=0.10$ & $D=0.17$ & - & - \\
& p-value=0.99 & p-value=0.60 & - & - \\
\hline
\end{tabular}

D. Frequency of the reported outcomes of five and six with a monetary incentive to lie

\begin{tabular}{|l|c|c|}
\hline Religiosity & Females & Males \\
\hline Secular & $0.73^{\text {\#\# }}$ & $0.51^{\text {\# }}$ \\
& {$[0.58,0.88](0.53,0.93)$} & {$[0.35,0.67](0.30,0.73)$} \\
\hline Orthodox & 0.48 & 0.48 \\
& {$[0.29,0.67](0.23,0.73)$} & {$[0.32,0.63](0.28,0.67)$} \\
\hline Ultra-Orthodox & 0.38 & 0.31 \\
& {$[0.22,0.53](0.17,0.58)$} & {$[0.14,0.48](0.09,0.53)$} \\
\hline
\end{tabular}

Notes: Based on the experimental results and on Column (1) of table 3. The 95\% (99\%) confidence intervals are given in square (round) brackets. The K-S (Kolmogorov-Smirnov) test measures the maximum frequency difference between two distributions $(D)$. Rejection of the null hypothesis implies different distributions for the control and treatment groups. ${ }^{\#}$ significantly greater than 3.5 , the expected outcome in a fair die throw, at the 5\% level. ${ }^{\# \#}$ significantly greater than 3.5 at the $1 \%$ level. * significantly different from zero at the $10 \%$ level. ** significantly different from zero at the $5 \%$ level. $* * *$ significantly different from zero at the $1 \%$-level. 
Figure 1A: Distribution of Reported Outcomes by Religiosity - Females SECULAR FEMALES WITH MONETARY INCENTIVE TO LIE (obs.=33)

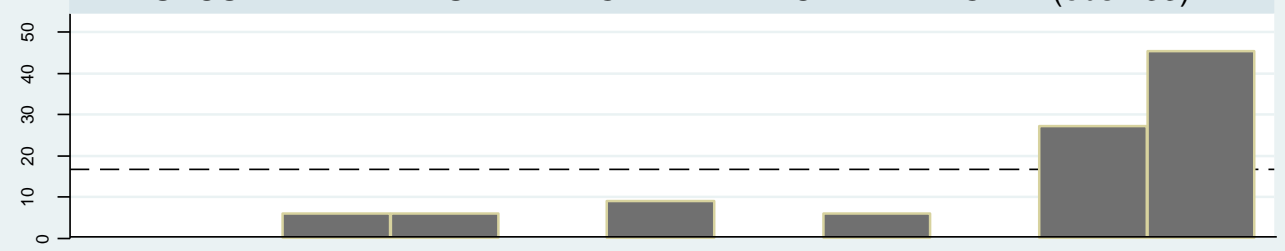

ORTHODOX FEMALES WITH MONETARY INCENTIVE TO LIE (obs.=27)

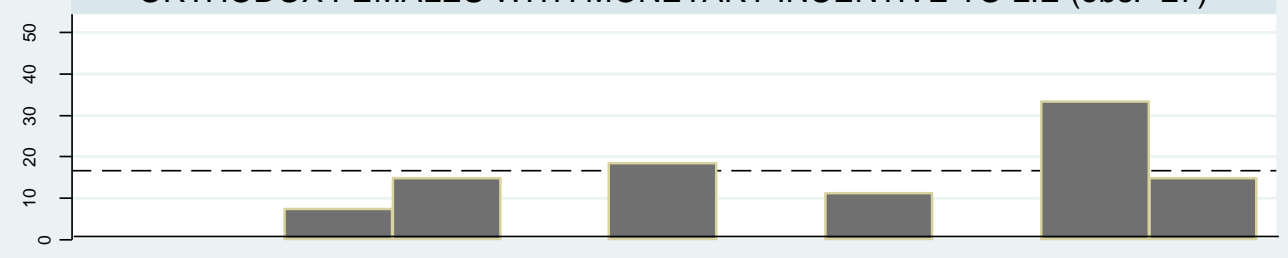

ULTRA-ORTHODOX FEMALES WITH MONETARY INCENTIVE TO LIE (obs.=37)

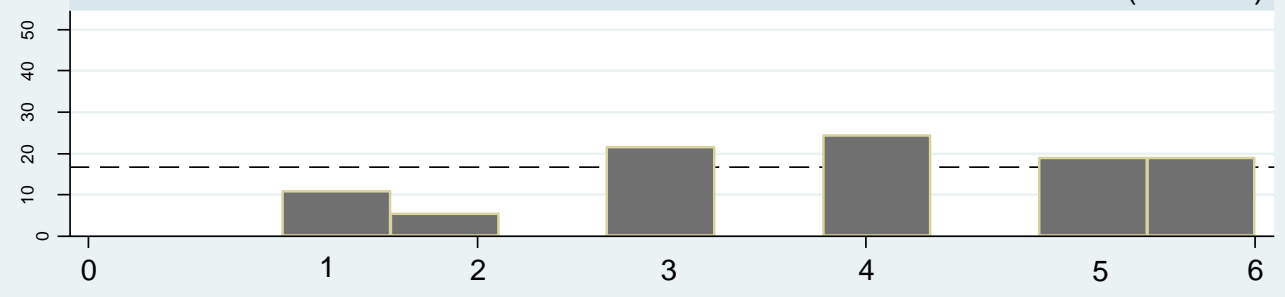

Figure 1B: Distribution of Reported Outcomes by Religiosity - Males SECULAR MALES WITH MONETARY INCENTIVE TO LIE (obs.=37)

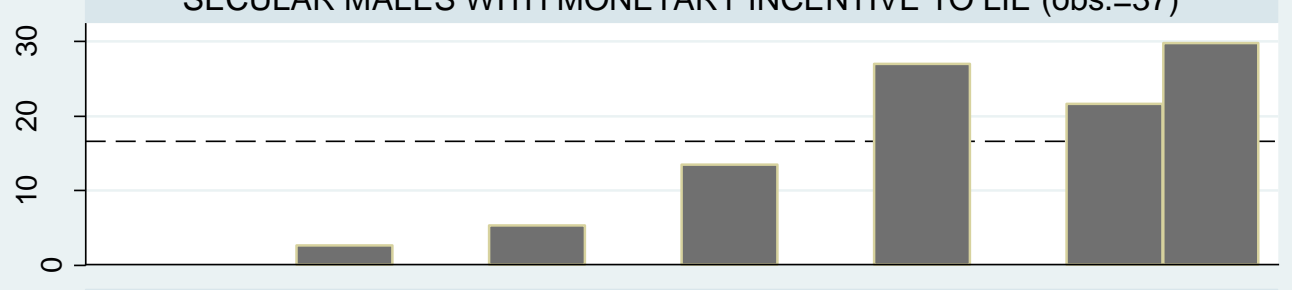

ORTHODOX MALES WITH MONETARY INCENTIVE TO LIE (obs.=42)
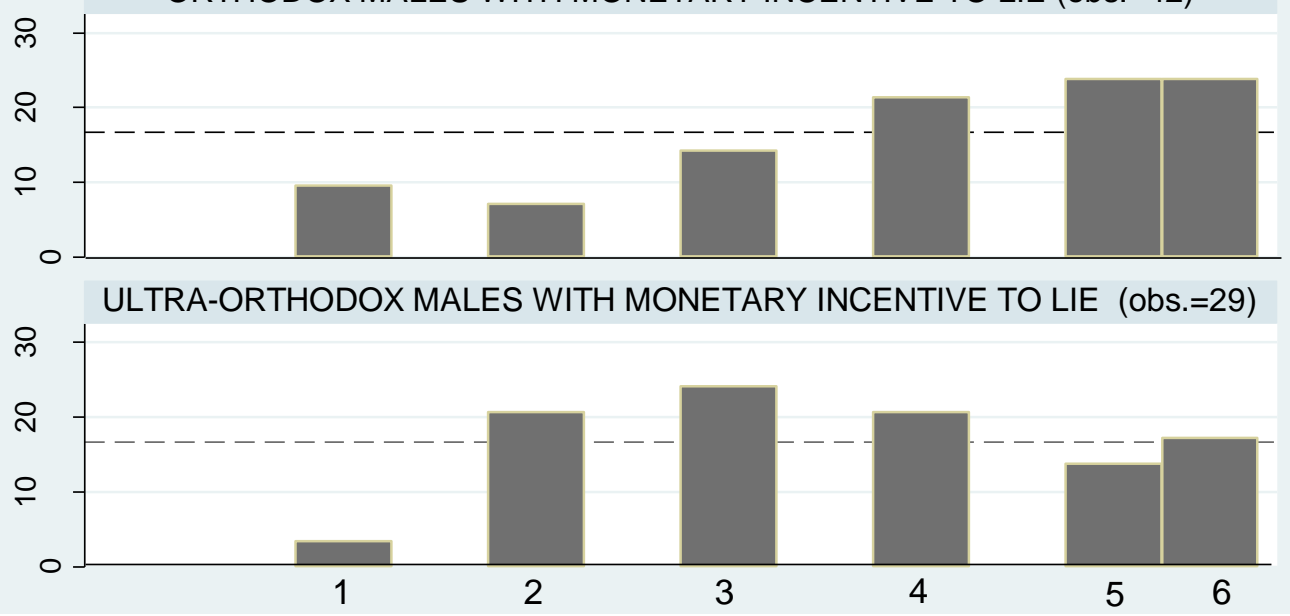

Notes: The subjects consisted of 97 females and 108 males. The dashed line represents the $\frac{1}{6}$ probability of obtaining any one of the outcomes in a fair die throw. 
Table 5: Reported Outcomes with a Monetary Incentive to Lie - Comparison between Selected Groups

A. Comparison between males and Orthodox females by age:

\begin{tabular}{|l|c|c|c|}
\hline Group & Age=20 & Age=25 & Age=30 \\
\hline Males & $4.57^{\text {\#\# }}$ & $4.36^{\text {\#\#\# }}$ & $4.15^{\text {\#\#\# }}$ \\
& {$[4.18,4.97]$} & {$[4.04,4.68]$} & {$[3.87,4.44]$} \\
& $(4.05,5.09)$ & $(3.95,4.78)$ & $(3.78,4.53)$ \\
\hline Orthodox & 3.88 & 3.88 & 3.88 \\
Females & {$[3.29,4.47]$} & {$[3.29,4.47]$} & {$[3.29,4.47]$} \\
& $(3.10,4.66)$ & $(3.10,4.66)$ & $(3.10,4.66)$ \\
\hline Difference & $0.69 *$ & 0.48 & 0.28 \\
& {$[-0.02,1.40]$} & {$[-0.19,1.15]$} & {$[-0.38,0.93]$} \\
& $(-0.25,1.63)$ & $(-0.40,1.37)$ & $(-0.59,1.14)$ \\
\hline
\end{tabular}

B. Comparison between males and ultra-Orthodox females by age:

\begin{tabular}{|l|c|c|c|}
\hline Group & Age=20 & Age=25 & Age=30 \\
\hline Males & $4.57^{\text {\#\#\# }}$ & $4.36^{\text {\#\#\# }}$ & $4.15^{\text {\#\#\# }}$ \\
& {$[4.18,4.97]$} & {$[4.04,4.68]$} & {$[3.87,4.44]$} \\
& $(4.05,5.09)$ & $(3.95,4.78)$ & $(3.78,4.53)$ \\
\hline Ultra-Orthodox & 3.89 & 3.89 & 3.89 \\
females & {$[3.40,4.38]$} & {$[3.40,4.38]$} & {$[3.40,4.38]$} \\
& $(3.24,4.54)$ & $(3.24,4.54)$ & $(3.24,4.54)$ \\
\hline Difference & $0.68^{* *}$ & 0.47 & 0.26 \\
& {$[0.05,1.31]$} & {$[-0.11,1.06]$} & {$[-0.30,0.84]$} \\
& $(-015,1.51)$ & $(-0.30,1.25)$ & $(-0.48,1.02)$ \\
\hline
\end{tabular}

C. Differences between reports of 35-45 year old males and Orthodox females:

\begin{tabular}{|l|c|c|c|}
\hline Group & Age $=35$ & Age $=40$ & Age=45 \\
\hline Males & $3.95^{\mathrm{\# \#}}$ & 3.74 & 3.53 \\
& {$[3.63,4.26]$} & {$[3.35,4.13]$} & {$[3.04,4.02]$} \\
& $(3.53,4.36)$ & $(3.23,4.25)$ & $(2.89,4.18)$ \\
\hline Orthodox & 3.88 & 3.88 & 3.88 \\
females & {$[3.29,4.47]$} & {$[3.29,4.47]$} & {$[3.29,4.47]$} \\
& $(3.10,4.66)$ & $(3.10,4.66)$ & $(3.10,4.66)$ \\
\hline Difference & 0.07 & -0.14 & -0.35 \\
& {$[-0.60,0.74]$} & {$[-0.85,0.57]$} & {$[-1.11,0.42]$} \\
& $(-0.81,0.95)$ & $(-1.07,0.79)$ & $(-1.36,0.67)$ \\
\hline
\end{tabular}

D. Differences between reports of 35-45 year old males and ultra-Orthodox females:

\begin{tabular}{|l|c|c|c|}
\hline Group & Age=35 & Age=40 & Age=45 \\
\hline Males & $3.95^{\mathrm{\# \#}}$ & 3.74 & 3.53 \\
& {$[3.63,4.26]$} & {$[3.35,4.13]$} & {$[3.04,4.02]$} \\
& $(3.53,4.36)$ & $(3.23,4.25)$ & $(2.89,4.18)$ \\
\hline Ultra-Orthodox & 3.89 & 3.89 & 3.89 \\
females & {$[3.40,4.38]$} & {$[3.40,4.38]$} & {$[3.40,4.38]$} \\
& $(3.24,4.54)$ & $(3.24,4.54)$ & $(3.24,4.54)$ \\
\hline Difference & 0.06 & -0.15 & -0.36 \\
& {$[-0.52,0.64]$} & {$[-0.78,0.48]$} & {$[-0.34,1.05]$} \\
& $(-0.71,0.83)$ & $(-0.98,0.68)$ & $(-0.56,1.27)$ \\
\hline
\end{tabular}

Notes: The table presents projected values obtained from the experiment carried out simultaneously at the College of Management (a secular academic institution) and the Jerusalem College of Technology (a religious academic institution) on Tuesday, December 4, 2012. and using Column (4) of Table 3. The $95 \%$ (99\%) confidence intervals appear in the square (round) brackets. The K-S (KolmogorovSmirnov) test measures the maximum frequency difference between two distributions $(D)$. Rejection of the null hypothesis implies different distributions for the control and treatment groups. ${ }^{\#}$ significantly greater than 3.5 (the expected fair die throwing outcome) at the 5\% level. ${ }^{\# \#}$ significantly greater than 3.5 (the expected fair die throw) at the $1 \%$ level. * significantly different from zero at the $10 \%$ level. ** significantly different from zero at the $5 \%$-level. $* * *$ significantly different from zero at the $1 \%$ level 
Table 6: Estimation of Reported Outcomes with (without) a Monetary Incentive to Lie

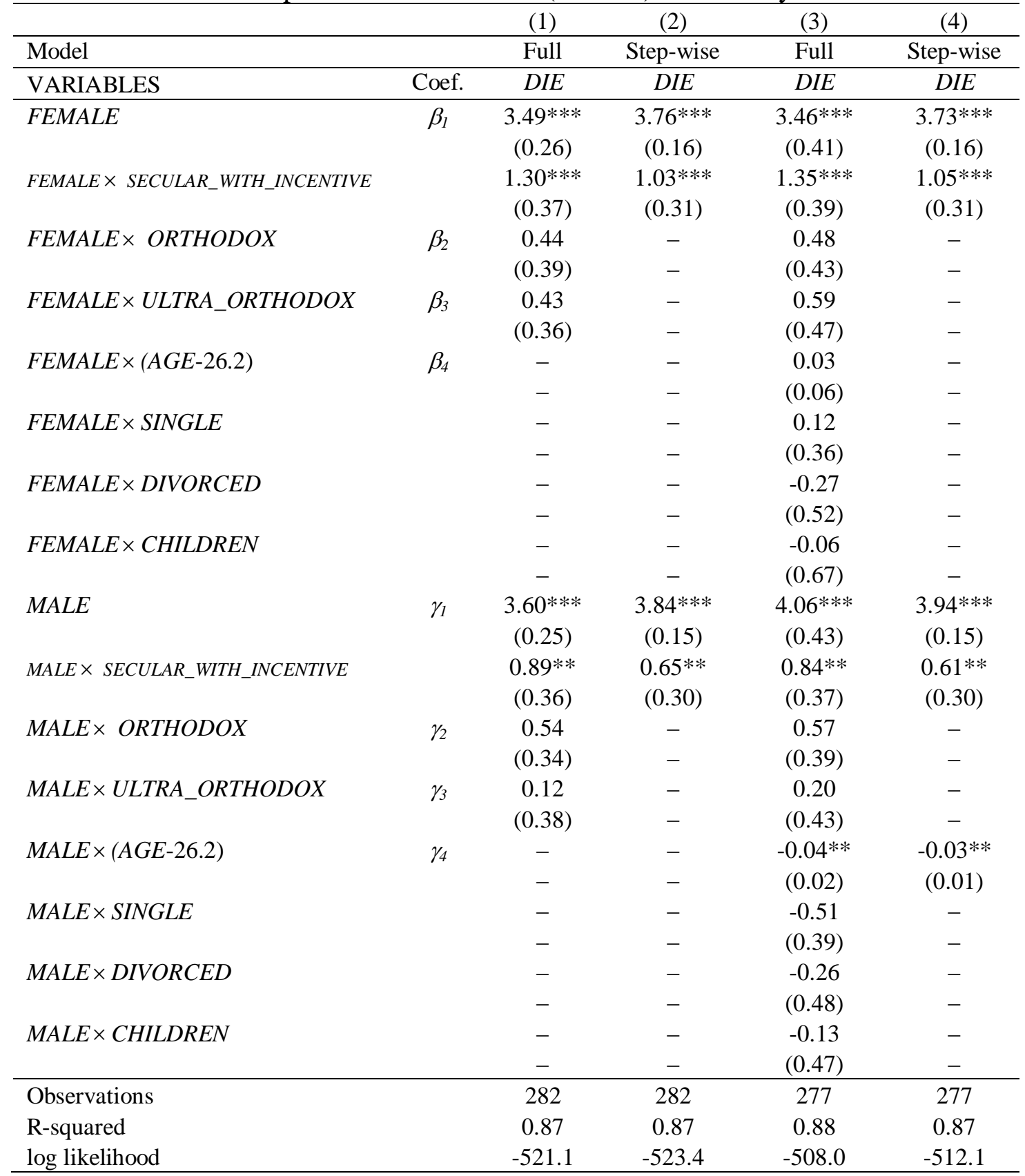

Notes: Results obtained for the treatment group (which were given a monetary incentive to lie) in the experiment carried out simultaneously at the College of Management and the Jerusalem College of Technology on Tuesday, December 4, 2012 and for the control group (which did not have a monetary incentive to lie) in the experiment carried out at the College of Management on Wednesday, October 23,2013 . The dependent variable in all the regressions is the reported outcome $(1,2,3,4,5$ or 6$)$. FEMALE and MALE (the base categories) equal 1 for secular females and males who received a fixed payment of 55 NIS regardless of the reported outcome and 0 otherwise. SECULAR_WITH_INCENTIVE, ORTHODOX and ULTRA_ORTHODOX equal 1 for secular, Orthodox and ultra-Orthodox participants respectively who were given a monetary incentive to lie and 0 otherwise. The age variable is measured in years where AGE $=26.2$ is the sample mean. In Columns (2) and (4), only significant coefficients (at the 5\% level) are presented. Columns (1) and (2) include only dummies for the treatment group (SECULAR_WITH_INCENTIVE, ORTHODOX and ULTRA_ORTHODOX where the control group is SECULAR_WITHOUT_INCENTIVE). Columns (3) and (4) also include socio-demographic control variables (AGE, SINGLE, DIVORCED, and CHILDREN).* significantly different from zero at the $10 \%$ level. ** significantly different from zero at the $5 \%$ level. $* * *$ significantly different from zero at the $1 \%$ level. 
Table 7: Reported Outcomes of Secular Subjects with and without a Monetary Incentive to Lie

A. Comparison between secular subjects with and without an incentive to lie:

\begin{tabular}{|c|c|c|c|c|c|}
\hline Religiosity & Incentive to Lie & Females & Males & Difference & $\mathrm{K}-\mathrm{S}$ test \\
\hline Secular & Yes & $\begin{array}{c}4.79^{\# \# \#} \\
{[4.26,5.32]} \\
(4.09,5.49)\end{array}$ & $\begin{array}{c}4.49^{\# \# \#} \\
{[3.98,4.99]} \\
(3.82,5.15)\end{array}$ & $\begin{array}{c}0.30 \\
{[-0.43,1.03]} \\
(-0.66,1.27)\end{array}$ & $\begin{array}{c}D=0.21 \\
\text { p-value }=0.34\end{array}$ \\
\hline Secular & No & $\begin{array}{c}3.49 \\
{[2.98,3.99]} \\
(2.82,4.15)\end{array}$ & $\begin{array}{c}3.60 \\
{[3.12,4.08]} \\
(2.96,4.24)\end{array}$ & $\begin{array}{c}-0.11 \\
{[-0.81,0.59]} \\
(-1.04,0.81)\end{array}$ & $\begin{array}{c}D=0.09 \\
\text { p-value }=0.99\end{array}$ \\
\hline Difference & & $\begin{array}{c}1.30 * * * \\
{[0.57,2.04]} \\
(0.33,2.27)\end{array}$ & $\begin{array}{c}0.89 * * \\
{[0.19,1.58]} \\
(-0.03,1.81)\end{array}$ & $\begin{array}{c}0.41 \\
{[-0.60,1.43]} \\
(-0.92,1.75)\end{array}$ & - \\
\hline K-S test & & $\begin{array}{c}D=0.43 * * * \\
\text { p-value }=0.00\end{array}$ & $\begin{array}{c}D=0.23 \\
\text { p-value }=0.20\end{array}$ & - & $\begin{array}{l}- \\
-\end{array}$ \\
\hline
\end{tabular}

B. Frequency of reporting five and six with and without a monetary incentive to lie

\begin{tabular}{|c|c|c|c|}
\hline Religiosity & Incentive to Lie & Females & Males \\
\hline Secular & Yes & $\begin{array}{c}0.73^{\# \# \#} \\
{[0.58,0.88]} \\
(0.53,0.93)\end{array}$ & $\begin{array}{c}0.51^{\#} \\
{[0.35,0.67]} \\
(0.30,0.73)\end{array}$ \\
\hline Secular & No & $\begin{array}{c}0.30 \\
{[0.15,0.44]} \\
(0.10,0.49)\end{array}$ & $\begin{array}{c}0.35 \\
{[0.20,0.50]} \\
(0.16,0.54)\end{array}$ \\
\hline
\end{tabular}

Notes: Results based on Column (1) of Table 6 and the merging of the treatment group (with a monetary incentive to lie) in the experiment carried out simultaneously at the College of Management and the Jerusalem College of Technology on Tuesday, December 4, 2012 and the control group (without a monetary incentive to lie) in the experiment carried out at the College of Management on Wednesday, October 23, 2013). The 95\% (99\%) confidence intervals appear in square (round) brackets. The K-S (Kolmogorov-Smirnov) test measures the maximum frequency difference between two distributions $(D)$. Rejection of the null hypothesis implies different distributions for the control and treatment groups. \#\# significantly greater than 3.5 (the expected fair die throwing outcome) at the $5 \%$ level. \#\# significantly greater than 3.5 (the expected fair die throwing outcome) at the $1 \%$ level. * significantly different from zero at the $10 \%$ level. $* *$ significantly different from zero at the $5 \%$ level. *** significantly different from zero at the $1 \%$ level. 
Figure 2A: Distribution of Reported Outcomes by Level of Religiosity - Females SECULAR FEMALES WITH MONETARY INCENTIVE TO LIE (obs=33)

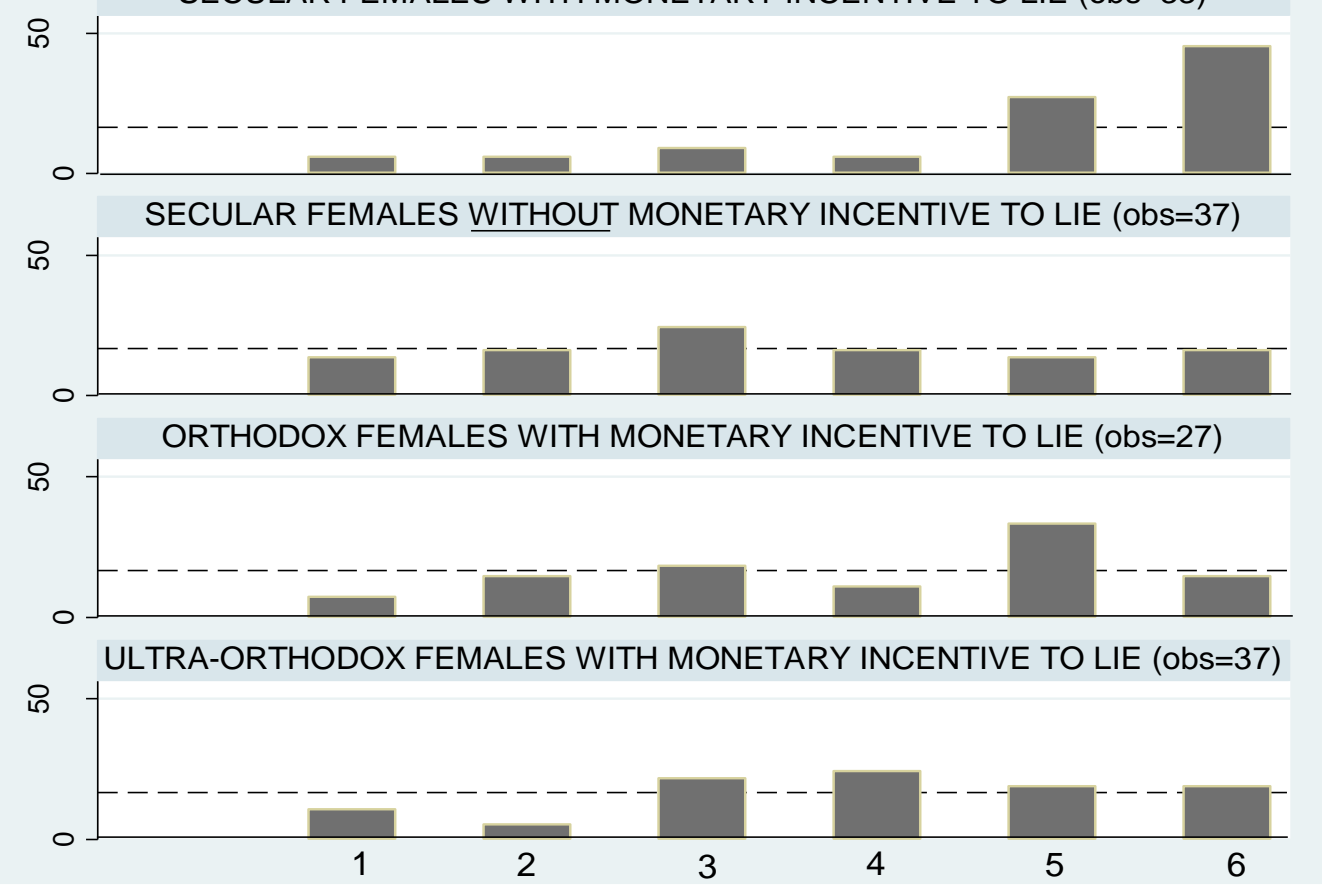

Figure 2B: Distribution of Reported Outcomes by Level of Religiosity - Males

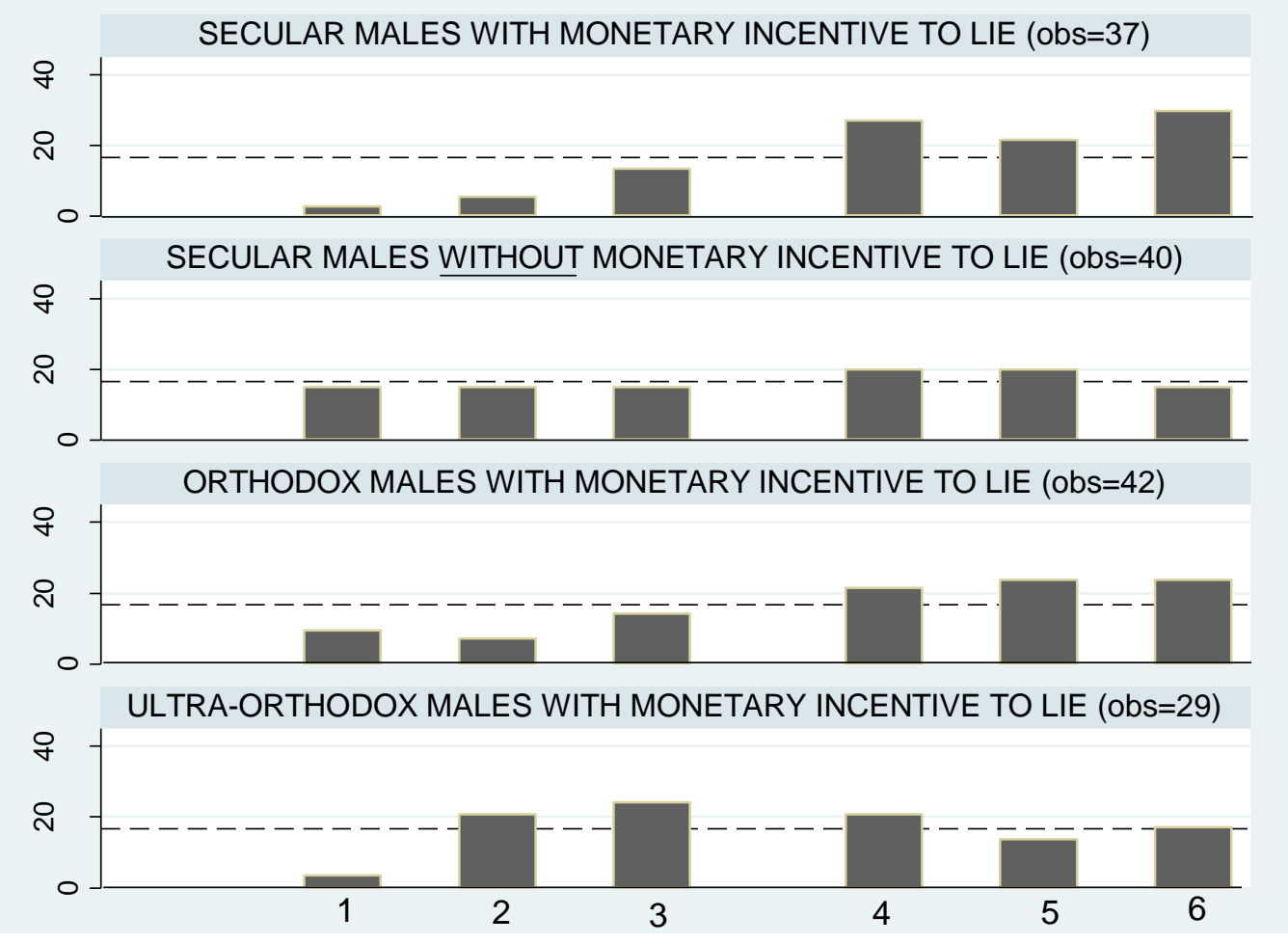

Notes: The subjects consisted of 134 females and 148 males. Results were obtained by merging the treatment group (with a monetary incentive to lie) in the experiment carried out simultaneously at the College of Management, and the Jerusalem College of Technology on Tuesday, December 4, 2012 and the control group (without a monetary incentive to lie) in the experiment carried out at the College of Management on Wednesday, October 23, 2013. The dashed line represents the $\frac{1}{6}$ probability of obtaining any one of the outcomes in a fair die throw. 
Table 8: Reported Outcomes with (without) a Monetary Incentive to Lie

\begin{tabular}{|c|c|c|c|c|c|}
\hline & & (1) & (2) & (3) & (4) \\
\hline Model & & Full & Step-wise & Full & Step-wise \\
\hline VARIABLES & Coef. & DIE & DIE & $D I E$ & $D I E$ \\
\hline FEMALE & $\beta_{l}$ & $\begin{array}{c}3.68 * * * \\
(0.26)\end{array}$ & $\begin{array}{c}3.72 * * * \\
(0.15)\end{array}$ & $\begin{array}{c}3.66 * * * * \\
(0.38)\end{array}$ & $\begin{array}{c}3.72 * * * * \\
(0.15)\end{array}$ \\
\hline FEMALE $\times$ SECULAR_WITH_INCENTIVE & & $\begin{array}{c}1.50 * * * \\
(0.36)\end{array}$ & $\begin{array}{c}1.46^{* * * *} \\
(0.29)\end{array}$ & $\begin{array}{c}1.56^{* * * *} \\
(0.51)\end{array}$ & $\begin{array}{c}1.46^{* * * *} \\
(0.29)\end{array}$ \\
\hline FEMALE $\times$ ORTODOX & $\beta_{2}$ & $\begin{array}{c}0.18 \\
(0.35)\end{array}$ & $\begin{array}{l}- \\
-\end{array}$ & $\begin{array}{c}0.16 \\
(0.43)\end{array}$ & - \\
\hline FEMALE $\times$ ULTRA_ORTHODOX & $\beta_{3}$ & $\begin{array}{l}-0.06 \\
(0.36)\end{array}$ & $\begin{array}{l}- \\
-\end{array}$ & $\begin{array}{l}-0.19 \\
(0.52)\end{array}$ & - \\
\hline$F E M A L E \times(A G E-26.6)$ & $\beta_{4}$ & $\begin{array}{l}- \\
-\end{array}$ & $\begin{array}{l}- \\
- \\
-\end{array}$ & $\begin{array}{c}0.02 \\
(0.03)\end{array}$ & $\begin{array}{l}- \\
- \\
-\end{array}$ \\
\hline$F E M A L E \times$ SINGLE & & $\begin{array}{l}- \\
-\end{array}$ & $\begin{array}{l}- \\
-\end{array}$ & $\begin{array}{l}-0.13 \\
(0.34)\end{array}$ & $\begin{array}{l}- \\
-\end{array}$ \\
\hline FEMALE $\times$ DIVORCED & & $\begin{array}{l}- \\
-\end{array}$ & - & $\begin{array}{l}1.29 \\
(0.87)\end{array}$ & - \\
\hline FEMALE $\times$ CHILDREN & & $\begin{array}{l}- \\
-\end{array}$ & - & $\begin{array}{c}0.11 \\
(0.40)\end{array}$ & - \\
\hline$M A L E$ & $\gamma_{1}$ & $\begin{array}{c}3.32 * * * \\
(0.27)\end{array}$ & $\begin{array}{c}3.73 * * * \\
(0.15)\end{array}$ & $\begin{array}{c}3.27 * * * \\
(0.46)\end{array}$ & $\begin{array}{c}3.70 * * * \\
(0.15)\end{array}$ \\
\hline MALE $\times$ SECULAR_WITH_INCENTIVE & & $\begin{array}{c}1.25 * * * \\
(0.37)\end{array}$ & $\begin{array}{c}0.85^{* * * *} \\
(0.29)\end{array}$ & $\begin{array}{c}1.46^{* * * *} \\
(0.54)\end{array}$ & $\begin{array}{c}0.88 * * * \\
(0.29)\end{array}$ \\
\hline MALE $\times$ ORTHODOX & $\gamma_{2}$ & $\begin{array}{c}0.58 \\
(0.37)\end{array}$ & - & $\begin{array}{l}0.77^{*} \\
(0.43)\end{array}$ & $\begin{array}{l}- \\
-\end{array}$ \\
\hline MALE $\times$ ULTRA_ORTHODOX & $\gamma_{3}$ & $\begin{array}{c}0.58 \\
(0.37)\end{array}$ & - & $\begin{array}{c}0.82 \\
(0.54)\end{array}$ & $\begin{array}{l}- \\
-\end{array}$ \\
\hline$M A L E \times(A G E-26.6)$ & $\gamma_{4}$ & - & - & $\begin{array}{c}0.00 \\
(0.03)\end{array}$ & - \\
\hline$M A L E \times$ SINGLE & & $\begin{array}{l}- \\
-\end{array}$ & - & $\begin{array}{c}0.11 \\
(0.39)\end{array}$ & - \\
\hline MALE $\times$ DIVORCED & & $\begin{array}{l}- \\
-\end{array}$ & $\begin{array}{l}- \\
-\end{array}$ & $\begin{array}{l}-0.95 \\
(1.07)\end{array}$ & - \\
\hline$M A L E \times C H I L D R E N$ & & $\begin{array}{l}- \\
- \\
\end{array}$ & $\begin{array}{l}- \\
- \\
\end{array}$ & $\begin{array}{l}-0.25 \\
(0.47)\end{array}$ & $\begin{array}{l}- \\
- \\
\end{array}$ \\
\hline $\begin{array}{l}\text { Observations } \\
\text { R-squared } \\
\text { log likelihood }\end{array}$ & & $\begin{array}{c}253 \\
0.89 \\
-444.9\end{array}$ & $\begin{array}{c}253 \\
0.89 \\
-446.8\end{array}$ & $\begin{array}{c}248 \\
0.89 \\
-435.0\end{array}$ & $\begin{array}{c}248 \\
0.89 \\
-439.5\end{array}$ \\
\hline
\end{tabular}

Notes: Results of the experiment carried out at the Carmel Academic Center on Tuesday, November 12, 2013. The experiment was carried out among secular students who were randomly assigned to the treatment group (with a monetary incentive to lie) or the control group (without a monetary incentive to lie). The dependent variable in all the regressions is the reported outcome of throwing a fair die $(1,2,3,4,5$ or 6$) . F E M A L E$ and MALE (the base categories) equal 1 for secular females and males respectively who were paid a fixed sum of 55 NIS regardless of the reported outcome and 0 otherwise. SECULAR_WITH_INCENTIVE, ORTHODOX and ULTRA_ORTHODOX equal 1 for secular, Orthodox and ultra-Orthodox subjects respectively who were given a monetary incentive to lie and 0 otherwise. The age variable is measured in years where AGE $=26.2$ is the sample mean. In Columns (2) and (4), only significant coefficients (at the 5\% level) are presented. Columns (1) and (2) include only dummies for the treatment group (SECULAR_WITH_INCENTIVE, ORTHODOX and ULTRA_ORTHODOX where the control group is SECULAR_WITHOUT_INCENTIVE). Columns (3) and (4) also include socio-demographic control variables (AGE, SINGLE, DIVORCED and CHILDREN). * significantly different from zero at the $10 \%$ level. ** significantly different from zero at the $5 \%$ level. *** significantly different from zero at the $1 \%$ level. 
Table 9: Reported Outcomes with and without a Monetary Incentive to Lie

A. Comparison between secular subjects with and without an incentive to lie:

\begin{tabular}{|c|c|c|c|c|c|}
\hline Religiosity & $\begin{array}{c}\text { Incentive to } \\
\text { Lie }\end{array}$ & Females & Males & Difference & $\mathrm{K}-\mathrm{S}$ test \\
\hline Secular & Yes & $\begin{array}{c}5.18^{\# \#} \\
{[4.88,5.48]} \\
(4.78,5.59)\end{array}$ & $\begin{array}{c}4.57^{\# \#} \\
{[4.13,5.02]} \\
(3.98,5.17)\end{array}$ & $\begin{array}{c}0.61 * * \\
{[0.08,1.13]} \\
(-0.09,1.30)\end{array}$ & $\begin{array}{c}D=0.24 \\
\text { p-value }=0.28\end{array}$ \\
\hline Secular & $\mathrm{No}$ & $\begin{array}{c}3.68 \\
{[3.05,4.30]} \\
(2.84,4.52)\end{array}$ & $\begin{array}{c}3.32 \\
{[2.67,3.97]} \\
(2.44,4.20)\end{array}$ & $\begin{array}{c}0.36 \\
{[-0.53,1.24]} \\
(-0.82,1.53)\end{array}$ & $\begin{array}{c}D=0.19 \\
\text { p-value }=0.59\end{array}$ \\
\hline Difference & & $\begin{array}{c}1.50 * * * \\
{[0.84,2.17]} \\
(0.62,2.39)\end{array}$ & $\begin{array}{c}1.25 * * * \\
{[0.50,2.01]} \\
(0.25,2.25)\end{array}$ & $\begin{array}{c}0.25 \\
{[-0.74,1.24]} \\
(-1.06,1.56)\end{array}$ & - \\
\hline K-S test & & $\begin{array}{c}D=0.43 * * * \\
\text { p-value }=0.00\end{array}$ & $\begin{array}{c}D=0.40^{* *} \\
\text { p-value }=0.01\end{array}$ & $\begin{array}{l}- \\
-\end{array}$ & $\begin{array}{l}- \\
-\end{array}$ \\
\hline
\end{tabular}

B. Comparison between secular and Orthodox subjects with an incentive to lie:

\begin{tabular}{|l|c|c|c|c|}
\hline \multirow{2}{*}{ Religiosity } & Females & Males & Difference & K-S test \\
\hline Secular & $5.18^{\# \# \#}$ & $4.57^{\# \# \#}$ & $0.61^{* *}$ & $D=0.24$ \\
& {$[4.88,5.48]$} & {$[4.13,5.02]$} & {$[0.08,1.13]$} & p-value=0.28 \\
& $(4.78,5.59)$ & $(3.98,5.17)$ & $(-0.09,1.30)$ & \\
\hline Orthodox & 3.85 & 3.90 & -0.05 & $D=0.09$ \\
& {$[3.30,4.41]$} & {$[3.33,4.47]$} & {$[-0.83,0.74]$} & p-value=0.99 \\
& $(3.10,4.60)$ & $(3.13,4.67)$ & $(-1.09,1.00)$ & \\
\hline Difference & $1.33^{* * *}$ & $0.67 *$ & 0.66 & - \\
& {$[0.70,1.96]$} & {$[-0.03,1.38]$} & {$[-0.28,1.58]$} & - \\
& $(0.50,2.16)$ & $(-0.26,1.61)$ & $(-0.58,1.88)$ & - \\
\hline K-S test & $D=0.41^{* * *}$ & $D=0.19$ & - & - \\
& p-value=0.00 & p-value $=0.54$ & - & - \\
\hline
\end{tabular}

C. Comparison between secular and ultra-Orthodox subjects with an incentive to lie:

\begin{tabular}{|c|c|c|c|c|}
\hline Religiosity & Females & Males & Difference & $\mathrm{K}-\mathrm{S}$ test \\
\hline Secular & $\begin{array}{c}5.18^{\# \# \#} \\
{[4.88,5.48]} \\
(4.78,5.59) \\
\end{array}$ & $\begin{array}{c}4.57^{\# \# \#} \\
{[4.13,5.02]} \\
(3.98,5.17) \\
\end{array}$ & $\begin{array}{c}0.61 * * \\
{[0.08,1.13]} \\
(-0.09,1.30)\end{array}$ & $\begin{array}{c}D=0.24 \\
\text { p-value }=0.28\end{array}$ \\
\hline Ultra-Orthodox & $\begin{array}{c}3.60 \\
{[3.12,4.08]} \\
(2.96,4.24)\end{array}$ & $\begin{array}{c}3.90 \\
{[3.41,4.40]} \\
(3.24,4.57)\end{array}$ & $\begin{array}{c}-0.30 \\
{[-0.98,0.37]} \\
(-1.20,0.59)\end{array}$ & $\begin{array}{c}D=0.16 \\
\text { p-value }=0.82\end{array}$ \\
\hline Difference & $\begin{array}{c}1.58 * * * \\
{[1.04,2.12]} \\
(0.86,2.30) \\
\end{array}$ & $\begin{array}{c}0.67 * * \\
{[0.02,1.32]} \\
(-0.19,1.54) \\
\end{array}$ & $\begin{array}{c}0.91 * * \\
{[0.07,1.75]} \\
(-0.20,2.02) \\
\end{array}$ & $\begin{array}{l}- \\
-\end{array}$ \\
\hline K-S test & $\begin{array}{c}D=0.53 * * * \\
\text { p-value }=0.00\end{array}$ & $\begin{array}{c}D=0.24 \\
\text { p-value }=0.26\end{array}$ & $\begin{array}{l}- \\
-\end{array}$ & $\begin{array}{l}- \\
-\end{array}$ \\
\hline
\end{tabular}

D. Comparison between Orthodox and ultra-Orthodox subjects with an incentive to lie:

\begin{tabular}{|l|c|c|c|c|}
\hline Religiosity & Females & Males & Difference & K-S test \\
\hline Orthodox & 3.85 & 3.90 & -0.05 & $D=0.09$ \\
& {$[3.30,4.41]$} & {$[3.33,4.47]$} & {$[-0.83,0.74]$} & p-value $=0.99$ \\
& $(3.10,4.60)$ & $(3.13,4.67)$ & $(-1.09,1.00)$ & \\
\hline Ultra-Orthodox & 3.60 & 3.90 & -0.30 & $D=0.16$ \\
& {$[3.12,4.08]$} & {$[3.41,4.40]$} & {$[-0.98,0.37]$} & p-value $=0.82$ \\
& $(2.96,4.24)$ & $(3.24,4.57)$ & $(-1.20,0.59)$ & - \\
\hline Difference & 0.25 & 0.00 & 0.25 & - \\
& {$[-0.48,0.98]$} & {$[-0.74,0.74]$} & {$[-0.77,1.29]$} & - \\
\hline K-S test & $(-0.72,1.22)$ & $(-0.99,0.98)$ & $(-1.10,1.62)$ & - \\
& $D=0.14$ & $D=0.09$ & - & - \\
\hline
\end{tabular}


E. Frequency of reporting five and six when there is a monetary incentive to lie

\begin{tabular}{|l|c|c|c|}
\hline Religiosity & Incentive to Lie & Females & Males \\
\hline Secular & Yes & $0.79^{\text {\#\#\# }}$ & $0.55^{\text {\#\# }}$ \\
& & {$[0.64,0.94]$} & {$[0.37,0.72]$} \\
& & $(0.59,0.99)$ & $(0.30,0.79)$ \\
\hline Secular & No & 0.35 & 0.25 \\
& & {$[0.18,0.53]$} & {$[0.08,0.42]$} \\
& & $(0.11,0.60)$ & $(0.02,0.48)$ \\
\hline Orthodox & Yes & 0.38 & 0.47 \\
& & {$[0.21,0.55]$} & {$[0.28,0.66]$} \\
& & $(0.15,0.61)$ & $(0.21,0.72)$ \\
\hline Ultra-Orthodox & Yes & 0.27 & 0.42 \\
& & {$[0.10,0.43]$} & {$[0.24,0.60]$} \\
& & $(0.04,0.49)$ & $(0.17,0.67)$ \\
\hline
\end{tabular}

Notes: Results from the experiment carried out at the Carmel Academic Center on Tuesday, November 12, 2013. The 95\% (99\%) confidence intervals appear in square (round) brackets. The K-S (Kolmogorov-Smirnov) test measures the maximum frequency difference between two distributions $(D)$. Rejection of the null hypothesis implies different distributions for the control and treatment groups. \# significantly greater than 3.5 (the expected fair die throwing outcome) at the 5\% level. significantly greater than 3.5 (the expected fair die throwing outcome) at the 1\%-level. * significantly different from zero at the $10 \%$ level. $* *$ significantly different from zero at the $5 \%$ level. $* * *$ significantly different from zero at the $1 \%$ level. 
Figure 3A: Distribution of Reported Outcomes by Level of Religiosity - Females SECULAR FEMALES WITH MONETARY INCENTIVE TO LIE (obs.=33)
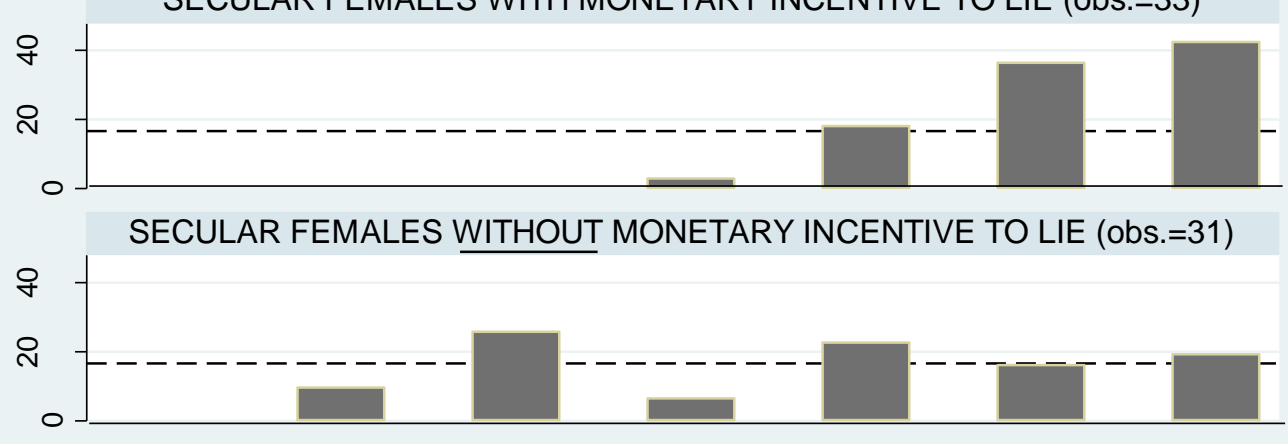

ORTHODOX FEMALES WITH MONETARY INCENTIVE TO LIE (obs.=34)

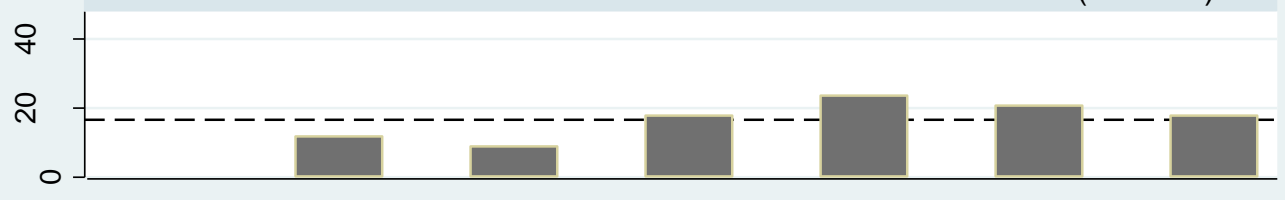

ULTRA-ORTHODOX FEMALES WITH MONETARY INCENTIVE TO LIE (obs.=31)

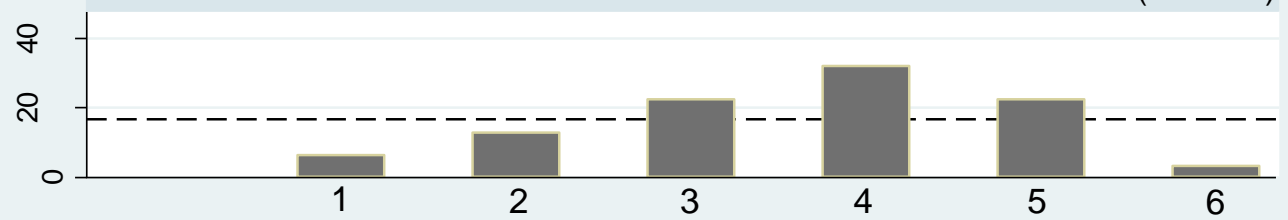

Figure 3B: Distribution of Reported Outcomes by Level of Religiosity - Males SECULAR MALES WITH MONETARY INCENTIVE TO LIE (obs.=33)

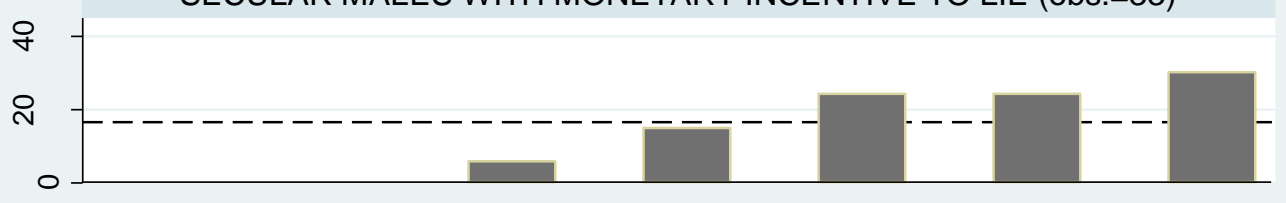

SECULAR MALES WITHOUT MONETARY INCENTIVE TO LIE (obs.=28)



ORTHODOX MALES WITH MONETARY INCENTIVE TO LIE (obs.=32)

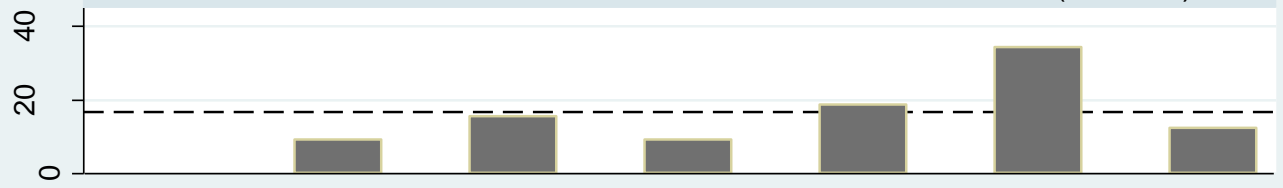

ULTRA-ORTHODOX MALES WITH MONETARY INCENTIVE TO LIE (obs.=31)



Notes: The experiment was carried out at the Carmel Academic Center on Tuesday, November 12, 2013. Subjects consisted of 129 females and 124 males.. The dashed line represents the one-sixth probability of obtaining any one of the outcomes in a fair die throw. 
Appendix A: Instructions Received by Subjects (translated from Hebrew)

Good morning,

In this experiment, you are requested to throw a die once while concealed behind a curtain. You are then requested to report the outcome to the experimenter and to hand him your filled-in questionnaire. You will receive a voucher for payment equal to 10 NIS multiplied by the result of the die throw which you reported (in addition to 20 NIS for participating). The possible payoffs are summarized in the following table:

\begin{tabular}{|l|c|c|c|c|c|c|}
\hline If you report: & 1 & 2 & 3 & 4 & 5 & 6 \\
\hline $\begin{array}{l}\text { You will receive the } \\
\text { following amount: }\end{array}$ & 10 NIS & 20 NIS & 30 NIS & 40 NIS & 50 NIS & 60 NIS \\
\hline $\begin{array}{l}\text { Fixed amount for } \\
\text { participating: }\end{array}$ & 20 NIS & 20 NIS & 20 NIS & 20 NIS & 20 NIS & 20 NIS \\
\hline Total payment: & 30 NIS & 40 NIS & 50 NIS & 60 NIS & 70 NIS & 80 NIS \\
\hline
\end{tabular}

Submit the voucher to the student union representative on your way out and in return you will receive the payment. At that point, you will have completed your part in the experiment and we would ask you to then leave the experiment area.

Good luck,

The experiment team 
Appendix B: Instructions for the Control Experiment (translated from Hebrew)

Good morning,

In this experiment, you are requested to throw a die once while concealed behind a curtain. You are then requested to report the outcome to the experimenter and to hand him your filled-in questionnaire. You will receive a voucher for payment of 55 NIS for participating in the experiment

Submit the voucher to the student union representative on your way out and in return you will receive payment. At that point, you will have completed your part in the experiment and we would ask that you then leave the experiment area.

Good luck,

The experiment team 
Appendix C:

First Experiment

C1. Number of Participants

\begin{tabular}{|l|c|c|c|}
\hline Religiosity & Females & Males & Total \\
\hline Secular & 33 & 37 & 70 \\
\hline Orthodox & 27 & 42 & 69 \\
\hline ultra-Orthodox & 37 & 29 & 66 \\
\hline Total & 97 & 108 & 205 \\
\hline
\end{tabular}

C2. Age Distribution in Years (Secular vs. Orthodox)

\begin{tabular}{|l|c|c|c|}
\hline Religiosity & Females & Males & Difference \\
\hline Secular & 24.21 & 28.24 & $-4.03 * *$ \\
& {$[21.78,26.64]$} & {$[25.95,30.54]$} & {$[-7.37,-0.69]$} \\
& $(21.00,27.42)$ & $(25.21,31.27)$ & $(-8.44,0.38)$ \\
\hline Orthodox & 23.13 & 29.96 & $-6.83 * * *$ \\
& {$[20.05,26.21]$} & {$[27.49,32.43]$} & {$[-10.78,-2.89]$} \\
& $(19.06,27.20)$ & $(26.70,33.23)$ & $(-12.05,-1.62)$ \\
\hline Difference & 1.08 & -1.72 & 2.80 \\
& {$[-3.07,5.24]$} & {$[-5.33,1.89]$} & {$[-2.70,8.31]$} \\
& $(-4.41,6.57)$ & $(-6.49,3.05)$ & $(-4.47,10.07)$ \\
\hline
\end{tabular}

C3. Age Distribution in Years (Secular vs. ultra-Orthodox)

\begin{tabular}{|l|c|c|c|}
\hline Religiosity & Females & Males & Difference \\
\hline Secular & 24.21 & 28.24 & $-4.03 * *$ \\
& {$[21.78,26.64]$} & {$[25.95,30.54]$} & {$[-7.37,-0.69]$} \\
& $(21.00,27.42)$ & $(25.21,31.27)$ & $(-8.44,0.38)$ \\
\hline Ultra-Orthodox & 21.04 & 32.66 & $-11.62 * * *$ \\
& {$[18.75,23.33]$} & {$[30.06,35.25]$} & {$[-15.07,-8.15]$} \\
& $(18.01,24.07)$ & $(29.23,36.07)$ & $(-16.18,-7.04)$ \\
\hline Difference & $3.17 *$ & $-4.42 * *$ & $7.59 * * *$ \\
& {$[-0.17,6.51]$} & {$[-7.87,-0.95]$} & {$[2.77,12.39]$} \\
& $(-1.24,7.58)$ & $(-8.98,0.16)$ & $(1.23,13.94)$ \\
\hline
\end{tabular}

Appendix D:

First and Second Experiment (Pooled Sample)

D1. Number of Participants:

\begin{tabular}{|l|c|c|c|c|}
\hline Religiosity & Incentive to Lie & Females & Males & Total \\
\hline Secular & Yes & 33 & 37 & 70 \\
\hline Secular & No & 37 & 40 & 77 \\
\hline Orthodox & Yes & 27 & 42 & 69 \\
\hline ultra-Orthodox & Yes & 37 & 29 & 66 \\
\hline Total & & 134 & 148 & 282 \\
\hline
\end{tabular}

D2. Age Distribution in Years (secular with and without an incentive to lie)

\begin{tabular}{|l|c|c|c|c|}
\hline Religiosity & Incentive to lie & Females & Males & Difference \\
\hline Secular & No & 24.51 & 25.97 & -1.46 \\
& & {$[22.25,26.77]$} & {$[23.77,28.18]$} & {$[-4.62,1.69]$} \\
& & $(21.54,27.49)$ & $(23.07,28.88)$ & $(-5.62,2.70)$ \\
\hline Secular & Yes & 24.21 & 28.24 & $-4.03 * *$ \\
& & {$[21.82,26.61]$} & {$[25.98,30.50]$} & {$[-7.32,-0.74]$} \\
& & $(21.06,27.37)$ & $(25.27,31.22)$ & $(-8.37,0.31)$ \\
\hline Difference & & 0.30 & -2.27 & 2.57 \\
& & {$[-2.99,3.59]$} & {$[-5.42,0.89]$} & {$[-1.99,7.13]$} \\
& & $(-4.04,4.64)$ & $(-6.43,1.89)$ & $(-3.44,8.58)$ \\
\hline
\end{tabular}

Notes: The statistics are for the subjects in the first experiment carried out simultaneously at the College of Management and the Jerusalem College of Technology on Tuesday, December 4, 2012 and in the second experiment carried out at the College of Management on Wednesday, October 23, 2013. The $95 \%(99 \%)$ confidence intervals appear in square (round) brackets. * significantly different from zero at the $10 \%$ level. $* *$ significantly different from zero at the $5 \%$ level. $* * *$ significantly different from zero at the $1 \%$ level. 


\section{Appendix E:}

\section{Third Experiment}

E1. Number of Participants

\begin{tabular}{|l|c|c|c|c|}
\hline Religiosity & Incentive to Lie & Females & Males & Total \\
\hline Secular & Yes & 33 & 33 & 66 \\
\hline Secular & No & 31 & 28 & 59 \\
\hline Orthodox & Yes & 34 & 32 & 66 \\
\hline ultra-Orthodox & Yes & 31 & 31 & 62 \\
\hline Total & & 129 & 124 & 253 \\
\hline
\end{tabular}

E2. Age Distribution in Years (secular with and without an incentive to lie)

\begin{tabular}{|l|c|c|c|c|}
\hline & $\begin{array}{c}\text { Incentive to } \\
\text { Religiosity }\end{array}$ & Females & Males & Difference \\
\hline Secular & Yes & 24.73 & 25.45 & -0.72 \\
& & {$[23.16,6.30]$} & {$[23.35,27.56]$} & {$[-1.72,0.27]$} \\
& & $(22.65,26.80)$ & $(22.67,28.64)$ & $(-2.05,0.60)$ \\
\hline Secular & No & 29.29 & 27.75 & 1.54 \\
& & {$[27.37,31.21]$} & {$[25.73,29.77]$} & {$[-1.24,4.32]$} \\
& & $(26.76,31.82)$ & $(25.09,30.41)$ & $(-2.13,5.21)$ \\
\hline Difference & & $-4.56^{* * *}$ & -2.30 & -2.26 \\
& & {$[-7.23,-1.89]$} & {$[-0.45,5.04]$} & {$[-6.10,1.56]$} \\
& & $(-8.08,-1.04)$ & $(-1.32,5.91)$ & $(-7.31,2.78)$ \\
\hline
\end{tabular}

E3. Age Distribution in Years (secular vs, Orthodox with an incentive to lie)

\begin{tabular}{|l|c|c|c|}
\hline Religiosity & Females & Males & Difference \\
\hline Secular & 24.73 & 25.45 & -0.72 \\
& {$[23.16,26.30]$} & {$[23.35,27.56]$} & {$[-1.72,0.27]$} \\
& $(22.65,26.80)$ & $(22.67,28.64)$ & $(-2.05,0.60)$ \\
\hline Orthodox & 26.24 & 28.90 & -2.66 \\
& {$[24.69,27.78]$} & {$[26.69,31.11]$} & {$[-5.87,0.54]$} \\
& $(24.19,28.28)$ & $(25.98,31.82)$ & $(-6.93,1.60)$ \\
\hline Difference & -1.51 & $-3.45^{* *}$ & 1.94 \\
& {$[-3.71,0.69]$} & {$[-6.49,-0.40]$} & {$[-1.77,5.64]$} \\
& $(-4.42,1.41)$ & $(-7.48,0.59)$ & $(-2.96,6.83)$ \\
\hline
\end{tabular}

E4. Age Distribution in Years (secular vs, ultra-Orthodox with an incentive to lie)

\begin{tabular}{|l|c|c|c|}
\hline Religiosity & Females & Males & Difference \\
\hline Secular & 24.73 & 25.45 & -0.72 \\
& {$[23.16,26.30]$} & {$[23.35,27.56]$} & {$[-1.72,0.27]$} \\
& $(22.65,26.80)$ & $(22.67,28.64)$ & $(-2.05,0.60)$ \\
\hline Ultra-Orthodox & 25.63 & 26.00 & -0.37 \\
& {$[23.99,27.28]$} & {$[23.83,28.17]$} & {$[-3.70,2.97]$} \\
& $(23.46,27.81)$ & $(23.13,28.87)$ & $(-4.80,4.07)$ \\
\hline Difference & -0.90 & -0.55 & -0.35 \\
& {$[-3.18,1.37]$} & {$[-3.57,2.48]$} & {$[-4.11,3.39]$} \\
& $(-3.92,2.10)$ & $(-4.55,3.46)$ & $(-5.31,4.59)$ \\
\hline
\end{tabular}

Notes: The statistics are for the subjects in the experiment carried out at the Carmel Academic Center on Tuesday, November 12, 2013. The 95\% (99\%) confidence intervals appear in square (round) brackets. * significantly different from zero at the $10 \%$ level. ** significantly different from zero at the $5 \%$ level. $* * *$ significantly different from zero at the $1 \%$ level. 